\title{
O DZIAŁANIACH PARATEATRALNYCH W EPOCE BRĄZU
}

\author{
ON PARATHEATRICAL ACTIVITIES IN THE BRONZE AGE
}

In this paper, paratheatrical activities are defined and archaeological finds that may confirm their presence are indicated. They are first of all manifested through the burial type and certain forms of artefacts. The analysis of the phenomenon focuses on the Bronze Age in Central Europe. It is discussed in the context of the following archaeological cultures: the Únětice culture, the Tumulus culture, and the Urnfield culture.

KEY WORDS: paratheater, the Bronze Age, burial rite

Znaleziska archeologiczne przynoszą informację o kulturze przeszłych społeczności w zależności od pytań, jakie stawiają im odkrywcy. Dlatego każda odmienna perspektywa badawcza sprawia, że wiedza staje się pełniejsza. Z pewnością kwestie dotyczące teatru w pradziejach Europy Środkowej nie należą do oczywistych pytań zadawanych przez archeologów. Ten rodzaj ekspresji artystycznej (ale także i sposób komunikowania się) spotykany jest jednak właściwie we wszystkich ludzkich społecznościach. Można powiedzieć, że to stała i niezbywalna część ludzkiej kultury. Ciało wraz z wytworami kultury materialnej stanowiło medium wykorzystywane $\mathrm{w}$ trakcie różnego rodzaju rytuałów. Tańce, śpiewy, wspólna konsumpcja, ceremonie pogrzebowe często mają charakter parateatru (Peterson Royse 2010, 247-268). Określenie to, podobnie jak teatr źródeł, po raz pierwszy zostało wprowadzone w latach 70. przez J. Grotowskiego (1979,
94-103). Początkowo dotyczyło pozascenicznych praktyk teatralnych (parateatr), później dostrzeżono obecność podobnych zjawisk w tradycyjnych rytuałach religijnych (teatr źródeł). Zagadnienie to stało się tematem osobnych badań (patrz Kocur 2013). Obecnie jako aktywność parateatralną określa się takie działania rytualne, które nastawione są na ekspresję, a ich wykonywanie ma oddziaływać na emocje odbiorców (widzów). Ich obecność jest więc niezbędna. Ponadto do ich przeprowadzenia potrzebne są umiejętności artystyczne - warsztat i technika, którą posługują się performerzy. Wydarzenia takie nie mogą więc mieć charakteru przypadkowej improwizacji - są powtarzalne, bo wynikają $\mathrm{z}$ wiedzy i tradycji obecnej w danej społeczności. Wskazuje się również, że rytuały stanowią realizacje określonych mitów (Stomma 2008, 166-167). Te ostatnie można więc rozumieć jako rodzaj scenariusza. Aktywność o charakterze teatralnym wynikała 
także ze sposobów funkcjonowania społeczności tradycyjnych. Analiza greckiej poezji archaicznej i eposów homeryckich pokazuje, że w strukturze osobowości poszczególnych jednostek właściwie brakuje ośrodka kierującego - ,ja” (Kowalski 1999, 148-152; Angutek 2003, 61-64). Egzystencja ludzka wyrażała się przez bycie postrzeganym przez innych (Vernant 2000; Segal 2000). Człowiek odnajdywał się w spojrzeniach innych - i to powodowało, że chciał być oglądanym (Mierzwiński 2012a, 82). Dodatkowo w wielu kulturach (a zwłaszcza wśród Indoeuropejczyków) widzieć znaczy wiedzieć (A. P. Kowalski 2001, 129-130). Działania parateatralne były więc bardzo nośną strategią komunikacyjną. Dotyczy to zwłaszcza społeczności nieznających pisma. Wydaje się więc, że należy się liczyć z powszechną obecnością takich obrzędów $\mathrm{w}$ pradziejach. Znaleziska archeologiczne pozwalają na ich rozpoznanie tylko częściowo. Zazwyczaj możliwy do odkrycia jest bowiem tylko zapis ostatniej - finałowej sceny, tj. wtedy, gdy artefakty zostają zdeponowane w ziemi. Można to porównać do momentu, gdy aktorzy na scenie wypowiedzieli już swoje kwestie i opada kurtyna. Aby znaleziska uznać za przejaw działalności parateatralnej, zastosowano dwa kryteria. Przede wszystkim muszą one wskazywać na powtarzalną działalność. Świadczy to o obecności ludzi posiadających odpowiednią wiedzę i umiejętności. Ponadto znaleziska muszą pokazywać, że dane działania były nastawione na obecność odbiorców (widzów). W domyśle miały także oddziaływać na ich emocje. Ta ostatnia kwestia musi jednak pozostać dyskusyjna - emocje dotyczą wszystkich ludzi, zależą jednak od kultury oraz predyspozycji psychicznych poszczególnych jednostek. Warto zaznaczyć, że tego typu podejście do aktywności rytualnej wbrew pozorom nie jest niczym nowym. Sztuka Adama Mickiewicza pt. „Dziady” to częściowo przeniesienie na deski sceniczne tradycyjnych obrzędów ludowych (patrz Kolankiewicz 1999). Tym bardziej jest to sugestywne, że dzieło to należy do kanonu literatury polskiej - i do pewnego stopnia ma charakter formujący dla całej kultury narodowej.

Rozbudowane formy działań parateatralnych i teatralnych w epoce brązu odnotowane zostały w krajach Bliskiego Wschodu i nad Morzem Śródziemnym. W tych rejonach to władca był odpowiedzialny za przygotowanie uczt, ofiar i związanych $\mathrm{z}$ nimi festiwali. W ten sposób rządzący manifestowali swoją pozycję. W Egipcie towarzyszyły temu występy muzykantów, tancerzy i akrobatów (Marinatos 2009, 33-34). Wydarzenia parateatralne odbywały się w specjalnie przygotowanej scenografii. W Grecji minojskiej w obrębie Pałacu w Knossos wydzielono przestrzeń przeznaczoną do przedstawień teatralnych (Rutkowski 1990, 13). Znane są też liczne przedstawienia ludzi skaczących przez byki (Hansen 2015, 151-152, ryc. 24-27) - co przypomina znaną do dziś corridę. Nie można przy tym wykluczyć obecności publicznie odprawianych rytuałów z wężami - co sugerują trzymające je kapłanki (Rutkowski 1990, 16). Jako scenerię do działań parateatralnych można widzieć również tzw. salę tronową z Knossos (Ałpatow 1976, 99, ryc. 76$)$. W miejscu tym odbywały się przeróżne rytuały, co potwierdzają znalezione przy tronie duże naczynia ofiarne. Ściany zdobione są freskami przedstawiającymi kwiaty oraz gryfy. Dwa takie wyobrażenia flankowały marmurowy tron. Budowa i lokalizacja tej sali powoduje, że mógł on być oświetlany przez promienie wschodzącego słońca. Scenografia służyła więc podkreśleniu statusu osoby władcy. Co charakterystyczne, sama koncepcja sali tronowej i jej lokalizacji w obrębie pałacu znajduje dokładne odpowiedniki w państwie Hetytów (opis i analiza patrz Marinatos 2009, 50-65, ryc. $2.23,4.1,4.2,4.3,4.5)$. Jako miejsce podobnych działań parateatralnych można także widzieć megarony (Rutkowski 1990, 29) znane w kulturze mykeńskiej. Za przejaw takiej działalności należy również uznać budowę grobowców dla władców oraz związane z nimi ceremonie pogrzebowe. Chyba najbardziej sugestywnym przykładem są egipskie piramidy. Również mykeńskie groby tolosowe posiadały rozbudowaną formę (patrz Schliemann 1878).

W wypadku Europy Środkowej to właśnie pochówki stanowią podstawowe źródło do rozpoznania działań parateatralnych. U schyłku neolitu i w początkach epoki brązu zaszło bardzo charakterystyczne zjawisko. Porzucono wcześniejszy zwyczaj wykonywania ceramicznych przedstawień figuralnych. Ekspresja plastyczna stała się niemal całkowicie niefiguratywna. Ponieważ obowiązywało tabu zakazujące przedstawień postaci ludzkiej - idee, wartości i emocje związane z człowiekiem wyrażano poprzez rzeczywiste ciało ludzkie, także martwe. W trakcie ceremonii pogrzebowych stało się ono ważnym rekwizytem i nośnikiem informacji.

W wypadku kultury unietyckiej stwierdzono, że zmarłych składano do grobów w określonych pozy- 


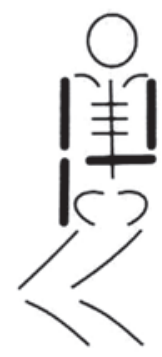

A

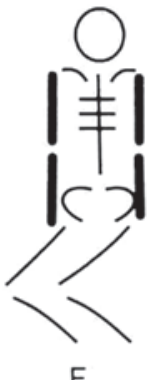

F

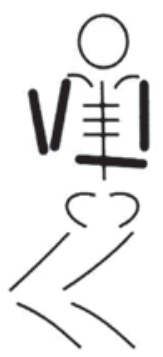

B

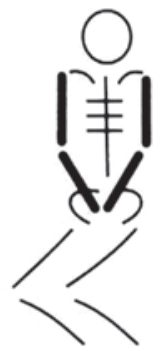

G

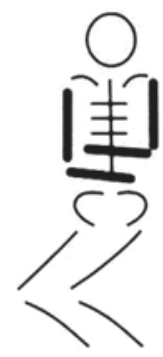

C

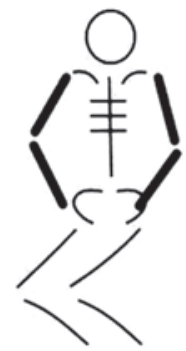

J

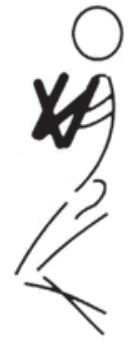

D

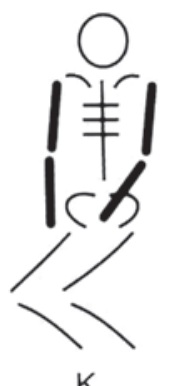

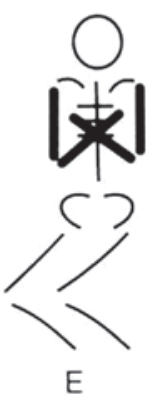

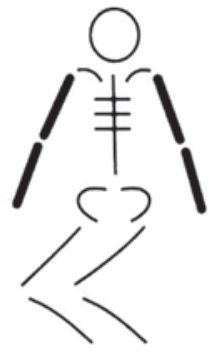

L

Ryc. 1. Sposoby układania zmarłych w grobach. Wg Häusler 1977

Fig. 1. Ways of positioning the dead in graves. After: Häusler 1977

cjach. Zjawisko to jest zresztą uchwytne u schyłku neolitu i w początkach epoki brązu na ogromnych obszarach Europy Środkowej i Wschodniej (ryc. 1) (Häusler 1977). Rozpoznano kilka powielanych układów oraz gestów wyrażonych sposobem ułożenia rąk. To właśnie powtarzalność wskazuje na obecność ludzi, którzy potrafili ułożyć ciała zmarłych w odpowiednich pozach. Nie były one przypadkowe, w ten sposób wyrażano znaczenia zrozumiałe dla widzów - uczestników rytuału pogrzebowego. Można również domniemywać, że śmierć i pogrzeb same w sobie były tymi elementami rytuału, które bardzo mocno oddziaływały na emocje.

Oprócz nadania odpowiedniej pozycji ciałom zmarłych ważnym elementem rytuału pogrzebowego było podkurczanie nóg. Dotyczyło to zdecydowanej większości pochówków. W niektórych wypadkach nienaturalne ułożenie sugeruje, że były one wiązane (Romanow 1973, 129-130), a może nawet i łamane w stawach. Wydaje się, że był to jeden z ważniejszych elementów, nomen omen, rytuałów przejścia. Zabieg ten kategorycznie uniemożliwiał bowiem chodzenie, a więc i powrót zmarłego do kondycji żywych. Oczywiście obrzęd ten miał charakter czysto „teatralny” - zmarły nie będzie chodził, nawet jeżeli nie będzie miał związanych nóg i połamanych kolan. W ten sposób odgrywano jedynie rytuał i przekazywano treści zrozumiałe dla uczestników ceremonii pogrzebowej. Ich sensu można jedynie się domyślać. W dużo późniejszych dziełach Homera pojawiają się sformułowania wskazujące na kolana jako niezbędny aspekt siły witalnej (Mierzwiński 2012a, 30). Człowiek pewnie stojący na nogach to wyraźnie widoczny przejaw życia i zdrowia. Jako przeciwieństwo można rozumieć leżącego - chorego lub martwego.

Kolejną cechą obrządku pogrzebowego było powtórne otwieranie grobów (ryc. 2: A) (Kadrow 2001, 133-134; Gralak 2007, 197). Wydaje się, że jednym z celów tej działalności było wybieranie kości zmarłych. Powtarzalność wskazuje na obecność ludzi posiadających wiedzę i umiejętności jak tego dokonać. Brak danych, by stwierdzić, czy działania takie były podejmowane na oczach innych członków społeczności. Jeśli tak - to najprawdopodobniej wywoływały silne emocje. Pojedyncze kości ludzkie znajdowane są także w obrębie domostw - najprawdopodobniej więc były one eksponowane. Niewykluczone, że trafiały tam właśnie w wyniku powtórnego otwierania grobów. Widać więc wyraźnie, że szczątki ludzkie zaczęto wykorzystywać jako rekwizyty w toczącej się grze społecznej. 

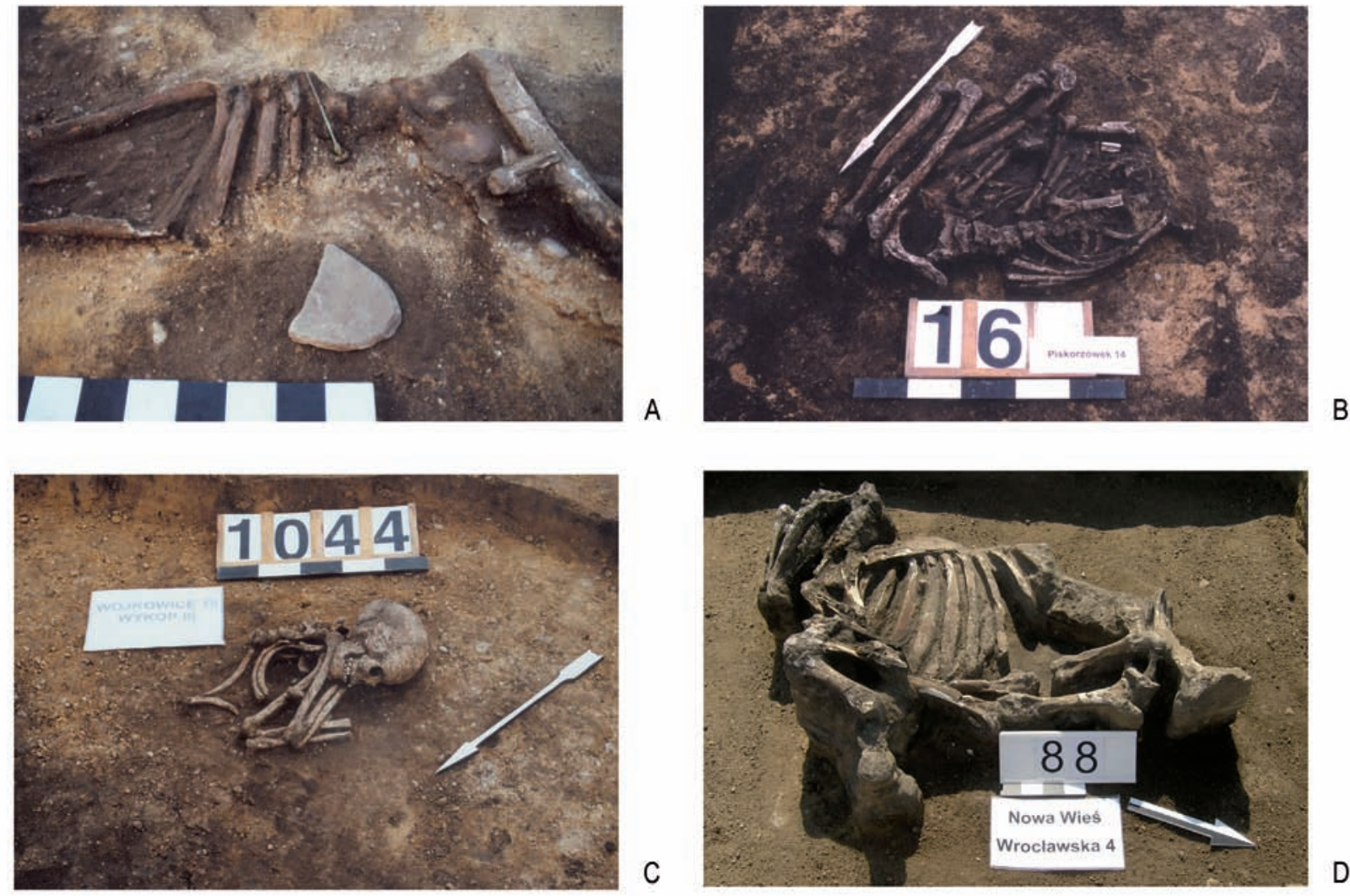

Ryc. 2. A - Wojkowice 15, pow. wrocławski, gr. 1058-III-00, otwierana jama grobowa; B - Piskorzówek 14, pow. oławski, gr. 16, pochówek ze szkieletem bez czaszki; C - Wojkowice 15, gr. 1044-III-00, pochówek cząstkowy;

D - Nowa Wieś Wrocławska 4, pow. wrocławski, pochówek bydlęcy. A, C wg Gralak 2007, B wg Gralak 2009a, D wg Gralak 2011

Fig. 2. A - Wojkowice 15, Wrocław district, gr. 1058-III-00, re-opened burial pit; B - Piskorzówek 14, Oława district, gr. 16, burial of a skeleton without a skull; C - Wojkowice 15, gr. 1044-III-00, fragmentary burial; D - Nowa Wieś Wrocławska 4, Wrocław district, cattle burial. A, C after Gralak 2007, B after Gralak 2009a, D after Gralak 2011

W przypadku kultury unietyckiej odnotowano także swego rodzaju fascynację głową ludzką. Znane są groby, w których znajdowano szkielety pozbawione czaszek (ryc. 2: B) (Primas 1977, 33-34; Gralak 2009a). Brak analiz, które wyjaśniałyby, czy zostały one usunięte w wyniku otwierania grobów, czy też przed pochówkiem dokonano dekapitacji żywego bądź martwego człowieka. Znane są również pochówki samych czaszek (Gralak 2009b). Wydaje się, że ten kompleks zjawisk jednoznacznie świadczy, że ta część ludzkiego ciała zajmowała szczególne miejsce w ówczesnym pojmowaniu cielesności. Znaleziska te nie pozostawiają także wątpliwości, że odprawiano różne rytuały, w których głowa lub czaszka ludzka była istotnym rekwizytem. Zarówno pozbawienie żywego lub martwego człowieka głowy, jak i jej pochówek miały cechy działań parateatralnych. Były powtarzalne, wymagały odpowiednich umiejętności - i jak inne pochówki najprawdopodobniej były odprawiane publicznie. Operowanie czaszką lub głową najprawdopodobniej oddziaływało także na emocje. Właśnie dlatego scena z czaszką ze sztuki Szekspira pt. „Hamlet” stanowi ikonę tego, co obecnie jest rozumiane jako teatr.

Następny rytuał o cechach parateatru to fragmentacja zwłok (Gralak 2007, 169, 190, ryc. 6061, 77-79). W obrębie kultury unietyckiej znane są bowiem pochówki cząstkowe (ryc. 2: C). Do grobu składano więc jedynie wybrane partie ciała, często zresztą przemieszane. Sam przebieg tego procesu nie jest jednoznacznie rozpoznany. Można domniemywać fragmentacji mechanicznej lub też wywołanej ekskarnacją części miękkich. W obu wypadkach proces ten musiał podlegać kontroli - nadzorowali go ludzie o odpowiednich umiejętnościach. 
Jako forma obrządku pogrzebowego najprawdopodobniej był dokonywany publicznie - oddziaływał więc na obserwatorów. Jak każda radykalna ingerencja w ludzkie ciało zapewne mocno oddziaływał na emocje. Wydaje się również, że rytuał fragmentacji zwłok polegał na odgrywaniu funkcjonujących wówczas mitów. Podobne wątki odnotowano W strefie śródziemnomorskiej i przynajmniej częściowo mogą one wyjaśniać to zjawisko. W ugaryckim eposie o Baalu (bóg burzy) pojawia się opis rozczłonkowania jego ciała przez Mot (władca umarłych). Jego szczątki trafiają w zaświaty dzięki bogini Shapash. Z pomocą bogini Anat zostaje jednak poskładany, a następnie zwycięża śmierć (Marinatos 2009, 171). Podobne elementy pojawiają się także w egipskich mitach związanych z Ozyrysem. Miał on być nauczycielem uprawy roli. Został zabity przez swojego brata Setha, a jego pokawałkowane ciało zostało wrzucone do Nilu. Odnalazła i poskładała je Izyda - co skutkowało jego wskrzeszeniem. Stał się władcą świata podziemnego i sędzią zmarłych. Manifestacją tego zjawiska był corocznie odprawiany rytual. $\mathrm{Na}$ jego ciele - wyobrażonym $\mathrm{w}$ postaci mumii - w bandażach kiełkowało i wzrastało zboże (Frazer 1962, 322-336). Warto też dodać, że ludność kultury unietyckiej zwłoki małych dzieci składała w dużych naczyniach (pitosach) przeznaczonych do przechowywania ziaren. Zwyczaj ten ma daleką - anatolijską genezę (Primas 1977, 81-82; Niesiołowska-Wędzka 1980, 34; Szmukier 1980, 11; Gediga 2003, 173). Ponadto w grobach znajdowane są także żarna i rozcieracze (Woźny 2005, 159-196). Wydaje się więc, że manipulacje zwłokami lub kośćmi wynikają jeszcze z wczesnoneolitycznych tradycji związanych z kultami agrarnymi. W generaliach stanowią one refleksję powstałą na skutek obserwacji cyklu rolniczego. Coroczny siew, wzrost, a następnie obumieranie zboża przyczyniły się do podobnego spojrzenia na życie i śmierć człowieka (patrz Eliade 1993, 319346). Oczywiście trudno zakładać, by mity o Baalu czy Ozyrysie były dokładnie znane twórcom kultury unietyckiej. Rytuały grobowe łączące fragmentację ciała i fascynację zbożem sugerują jednak, że znane były przynajmniej niektóre ich wątki.

Jako działalność parateatralną można także rozumieć składanie ofiar zwierzęcych. Z samego założenia był to rodzaj show - miał to oglądać domniemany zaświatowy odbiorca. W obrębie kultury unietyckiej na Dolnym Śląsku odnotowano dwa rodzaje pochówków zwierzęcych: całych (ryc. 2: D) i skonsumowanych (Gralak 2011). Te pierwsze stanowiły tylko groby bydlęce, które składano zarówno na osadach, jak i na cmentarzyskach. Ułożenie szkieletów oscylowało wzdłuż osi północ-południe. Za wyjątkiem pochówku ze Szczepankowic, głowy skierowane były na południe. Zwraca uwagę, że analogiczną orientację stwierdzono w wypadku pochówków ludzkich (Sarnowska 1969, 19; Kadrow 2001, 121). Z głową także związane były dodatkowe rytuały - jak dekapitacja w przypadku szkieletów z Milejowic i Nowej Wsi Wrocławskiej. Także one znajdują odpowiedniki w obrządku pogrzebowym stosowanym przez ludność kultury unietyckiej (Lorencova, Beneš, Podborsky 1987, 140-142). W przypadku pochówku ze Szczepankowic głowa odgięta była nienaturalnie do tyłu, co sugeruje, że zwierzęciu temu skręcono kark. Najprawdopodobniej zabiegi takie wynikają $\mathrm{z}$ wyobrażeń religijnych wartościujących tę część ciała. Dwukrotnie: w Nowej Wsi Wrocławskiej i w Szczepankowicach odnotowano także zabiegi związane z kończynami, prawdopodobnie $\mathrm{z}$ ich krępowaniem. Jak już wspomniano, ten sam zabieg stwierdzono także w wypadku pochówków ludzkich. Widać więc, że zachodzą pomiędzy nimi strukturalne zbieżności. Umiejętne zabicie zwierzęcia (zgodnie z określonym rytuałem), a także złożenie go do grobu, wymagało wiedzy i umiejętności. Sam akt połączony z pochówkiem najprawdopodobniej także był dokonywany publicznie. Miał więc oddziaływać na uczestników. Wydaje się także, że śmierć żywej istoty zawsze wywołuje silne emocje.

Na osadach w Wojkowicach i w Nowej Wsi Wrocławskiej odnotowano także jamy zawierające intencjonalnie złożone depozyty kości zwierzęcych - zapewne resztek konsumpcyjnych (Gralak 2011, 214-219, ryc. 4-6). W obiektach takich znaleziono szczątki bydła i świń, przy czym często należały one do młodych osobników. Odróżniają się wyraźnie od podobnych znalezisk z innych obiektów osadniczych. Stanowią prawdopodobnie całość szczątków danego zwierzęcia złożonych do specjalnie przygotowanej jamy. Domieszka innych kości była znikoma lub nie występowała zupełnie. Wydaje się, że w przypadku takich depozytów większość czynności było uwarunkowanych rytualnie. Zapewne stanowią one pozostałości obrzędowej uczty, w trakcie której spożywano zwierzęta będące jednocześnie ofiarami dla bóstwa. Jako takie stanowily więc element sacrum, a ich szczątki wymagały specjalnego traktowania. Obrzędy takie 
stanowią powszechny element wielu kultur. Znane są także depozyty pozostałych po nich kości (Moszyński 1967, 258; Makiewicz 1993, 75; Marciniak 1996, 141; Gralak 2011, 214-221). Konsumpcja zwierząt ofiarnych w świecie śródziemnomorskim posiadała jednoznaczne uzasadnienie mitologiczne. Był to jeden z darów Prometeusza, który oszukując Zeusa, bogom pozostawił jedynie thuszcz, skóry i kości (Hezjod, Teogonia, 545; patrz też: Graves 1974, 144-145). Tego typu depozyty świadczą więc o działaniach odprawianych zgodnie z określonym rytuałem, w którym uczestniczył kolektyw. Był on odgrywany wspólnie, a każdy uczestnik miał swoją rolę. Ucztę można więc potraktować jako rodzaj performensu. Warto dodać, że rytuał taki, określany jako „uczta kozła”, wspomniany został także w „Dziadach” A. Mickiewicza (1992, 13).

Krąg kultur mogiłowych to w dalszym ciągu okres niefiguratywnej ekspresji plastycznej. Podobnie jak wcześniej, aby wyrazić idee związane z cielesnością, musiano posługiwać się rzeczywistym ciałem. Nastąpiła jednak zmiana sposobu jego postrzegania. Bardzo wyraźnie czytelne jest zjawisko różnego sposobu traktowania zmarłych w zależności od statusu społecznego. $Z$ tego okresu bowiem pochodzą niemal wyłącznie pochówki kurhanowe (Gediga 1978, 145-146), zapewne należące do przedstawicieli elit (ryc. 3: A-B). Groby pozostałych członków społeczności pozostają nieznane. Tak więc ciała zmarłych miały wyraźnie zróżnicowany status.

W stosunku do I okresu EB następuje też zmiana obrządku. Zmarłych najczęściej układano na plecach w pozycji wyprostowanej. Co charakterystyczne, zanikają wszelkie rytuały wiążące się z ingerencją fizyczną w cielesność pochowanego. Nie odnotowano krępowania nóg, brak fragmentacji, brak manipulacji czaszkami, nie zauważono również wtórnego otwierania jam grobowych. Widać więc, że zwracano uwagę na zachowanie integralności ciała po śmierci. Bardzo charakterystyczne jest również wyposażenie pochówków. Stanowią je przedmioty z brązu (Gediga 1978, 146), a ich rodzaj wyraźnie łączy się z płcią zmarłego (Gedl 1975, 92). W przypadku mężczyzn jest to przede wszystkim broń, a kobiet - ozdoby (ryc. 3: C-M). Różnice między płciami były więc mocno podkreślone. Prawdopodobnie relacje takie stanowiły jeden z ważniejszych elementów konstruujących ówczesne społeczeństwo. Wydaje się, że pojawienie się dużej ilości bogato zdobionych przedmiotów z brązu niejako zastąpiło zjawisko wcześniejszych manipulacji szczątkami zmarłego.

Generalnie w II okresie EB kultura staje się bardziej performatywno-teatralna. Role społeczne przedstawicieli klasy elit odgrywane były przy pomocy rekwizytów (brązów). Bez tych przedmiotów ludzie tacy właściwie nie istnieli - tak jak przedstawiciele klas niższych, których groby pozostają nieznane. Najprawdopodobniej przedmioty metalowe stanowiły kod określający noszącą je osobę - okazywały jej miejsce w strukturze społecznej. Co charakterystyczne, niemal identyczne zjawisko odnotowano w antycznym teatrze greckim. Jako rekwizyty wykorzystywano przedmioty, które nazywano gnōrismanta. Według Arystotelesa miały one pozwalać widzom na rozpoznanie postaci. Były to właśnie broń i ozdoby - określały one przynależność rodową nosiciela (Arystoteles, Poetyka 16; Kowalska 2003, 33).

Używanie metalowych przedmiotów bezpośrednio tworzyło ludzi także pod względem fizycznym. Noszenie broni przez mężczyzn wymuszało odpowiednią postawę i ruchy. Ćwiczenia fizyczne związane z jej używaniem budowały natomiast muskulaturę. W ten sposób powstawał specyficzny sposób poruszania się (język ciała), odmienny niż pozostałych członków społeczności. Zakaz przed-

Na sąsiedniej stronie:

Ryc. 3. A, B - Grabonóg, pow. gostyński, kurhan. Kultura mogiłowa (przedłużycka), wybór przedmiotów brązowych: C - Śląsk; D - Namysłów. pow. loco; E - Cisek, pow. kędzierzyńsko-kozielski; F - Kietrz, pow. głubczycki;

G - Krzydlina Mała, pow. wołowski; H - Kruszyniec, pow. górowski; I-K - Rudna, pow. pilski; L - Zauschwitz, Kr. Borna; M - Studniska Dolne, pow. lubański. A wg Makarowicz 2017, ryc. 12, B wg Gediga 1978, ryc. 52, C-Mwg Gedl 1975

Fig. 3. A, B - Grabonóg, Gostyń district, mound burial. The tumulus culture (Pre-Lusatian), selection of bronze objects: C - Silesia; D - Namysłów, Namysłów district; E - Cisek, Kędzierzyn-Koźle district; F - Kietrz, Głubczyce district; G - Krzydlina Mała, Wołów district; H - Kruszyniec, Góra district; I-K - Rudna, Piła district; L - Zauschwitz,

Kr. Borna; M - Studniska Dolne, Lubań district. A after Makarowicz 2017, fig. 12, B after Gediga 1978, fig. 52, C-M after Gedl 1975 

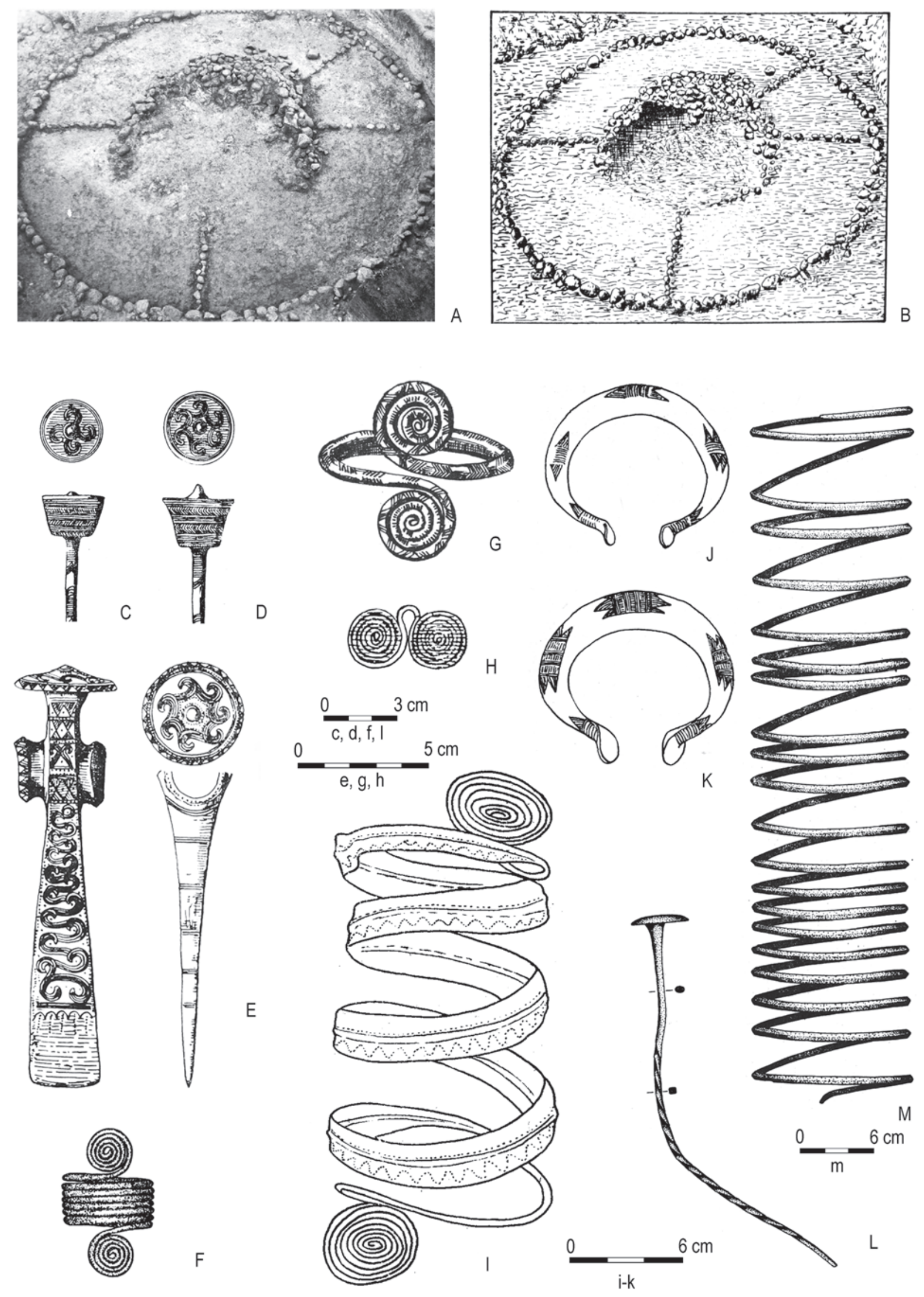
stawień figuralnych stanowi też jeden z powodów eksplozji zjawiska określonego jako warrior's beuty (patrz Treherne 1995). Ciało jako nośnik informacji (którego w wielu wypadkach nie można było niczym zastąpić) musiało być odpowiednio ozdabiane i pielęgnowane. $Z$ późniejszych czasów $\mathrm{z}$ terenów śródziemnomorskich wiadomo również, że wojownicy walczyli nago. Także najwcześniejsze zbroje naśladowały kształtem budowę ciała (Żygulski 1998, 29-31). Z kolei ciężkie ozdoby metalowe w dużej ilości nosiły głównie kobiety. To także wymuszało charakterystyczne ruchy. Zwłaszcza bransolety na nogach powodowały specyficzny sposób stawiania kroków. Ponadto ze względu na ciężar ruch musiał być odpowiednio spowolniony*. Do tego dochodzi jeszcze jeden aspekt - przedmioty z brązu, stukając o siebie, wydawały metaliczny dźwięk. Biblijny opis ubioru kapłana wskazuje, że mogło to być działanie całkowicie intencjonalne:

Dzwonek złoty i jabłko granatu będa następowaty na przemian dokoła na dolnych krajach sukni. I będzie miat ją na sobie Aaron podczas petnienia stużby, aby styszano dźwięk (...).

Księga Wyjścia 28: 34-35.

Można więc powiedzieć, że to ciała były dostosowywane do rekwizytów - a nie na odwrót. Tak więc - jak w niemieckim przysłowiu Kleider machen Leute (ubrania tworzą ludzi) - to strój budował widoczne i charakterystyczne postacie społeczne. Prawdopodobnie więc przedstawiciele elit pod względem fizycznym wyraźnie odróżniali się od pozostałych członków społeczności. Można ich było od razu rozpoznać - dzięki błyszczącym przedmiotom z brązu. Poruszali się inaczej, a do tego towarzyszyły im charakterystyczne dźwięki. Co istotne, w językach indoeuropejskich rdzenie słów dotyczących zdobienia, ubioru i dekorowania ciała można odnaleźć również w określeniach do-

* W wypadku tradycyjnej kultury Afryki subsaharyjskiej zaobserwowano (Herbert 1984, 217, 243), że noszenie od dziecka ciężkich bransolet na nogach (i nie tylko) wywoływało charakterystyczny sposób poruszania się. Określano go jako duck-like/bovine like encumbered walk. Czasami można to było zaobserwować w wypadku wodzów, najczęściej jednak dotyczyło kobiet. Pokazywało to, że dana osoba nie musi wykonywać żadnych prac fizycznych, co jednoznaczne wskazywało na najwyższą klasę społeczną. Ten sposób poruszania się próbowały naśladować osoby, które nigdy nie nosiły ciężkich ozdób. Miało to wyrażać ich wyższe aspiracje społeczne. tyczących świata i porządku. W języku greckim to

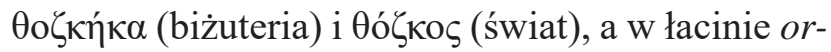
namentum (zdobienie) oraz ordo/ordino (świat, porządek) (Chausidis 2017, 933). Tak więc zdobienie ciała, w tym noszenie ozdób, wyrażało i odwzorowywało sposób rozumienia uniwersalnego ładu.

Ceremonia pogrzebowa w kręgu kultur mogiłowych to rozbudowany show. Ciało zmarłego (stanowiące swego rodzaju fetysz) - zaopatrzone w błyszczące metalowe rekwizyty - musiało być widoczne. Była to wizualizacja pozycji społecznej tych, którzy organizowali pogrzeb. Przedstawienie było bowiem przygotowane dla żywych - nie dla martwych. Ci ostatni nie mogli go przecież oglądać. Oczywiście sam przebieg obrzędu jest trudny do rekonstrukcji. Można jednak powiedzieć, że stanowił performens realizujący rytuał wyłączenia zmarłego ze wspólnoty żywych. Było to widowisko, które miało umocnić tożsamość wspólnoty po utracie jednego z jej członków. Ponadto ceremonia taka miała potwierdzić i legitymizować funkcjonującą hierarchię społeczną. Należy też dodać, że kurhany wraz $\mathrm{z}$ pamięcią o pochowanych trwale kształtowały przestrzeń, w której żyli twórcy kultur mogiłowych. Były one widoczne $\mathrm{z}$ daleka i prawdopodobnie stanowily punkty orientacyjne.

Jako rozbudowany spektakl można potraktować także wznoszenie kurhanu. Podobnie jak w wypadku pogrzebu, również takie działania mogły silnie oddziaływać na emocje. Sama budowa - zebranie materiału i usypanie kopca etc., wymagała oczywiście wysiłku fizycznego. Można się też liczyć z podziałem pracy. Najprawdopodobniej to przedstawiciele elit kierowali i zlecali budowę. Samo wykonanie spadało już na barki pozostałych członków społeczności. Proces ten w oczywisty sposób pokazywał relacje hierarchiczne. Kurhany były usypywane przez ludzi, którzy nigdy nie będą w nich pochowani, mało tego - w ogóle nie będą mieli grobów.

Kolejny element to znaczenia, które niósł ze sobą sam kurhan. Konstrukcja takiego grobowca stanowi przestrzeń sakralną, która posiada powtarzalne elementy strukturalne wyszczególnione i opisane przez S. Czarnowskiego (1963) i M. Eliadego (1996, 34-40). Granice między strefą sacrum i profanum zostały wyznaczone przez dookolny wieniec kamienny, ewentualnie mógł to być również rowek. Punkt centralny wyznaczony był przez pochówek, znajdujący się wewnątrz komory. Całość układu horyzontalnego lokalizowano w stosunku do stron świata lub innych stałych elementów 
postrzegania przestrzeni (np. astronomicznych). Wyrażano to poprzez orientację jamy grobowej i ciała zmarłego. W niektórych wypadkach - np. w Grabonogu podkreślano to dodatkowo poprzez układane z kamieni i zbiegające się w środku ramiona (ryc. 3). Uporządkowane elementy cechują także wertykalną strukturę tych budowli. Komory grobowe były wkopywane poniżej poziomu gruntu, na nim natomiast budowano nasyp sięgający w górę. Widać więc, że budowle takie odwzorowują trójstopniowy wertykalny podział na sferę niebiańską, ziemię i podziemia. Zgodnie z koncepcją M. Eliadego, przez punkt centralny strefy sacrum ma przebiegać axis mundii, która łączy te poziomy. Generalnie konstrukcja kurhanu powtarzała ówczesny sposób widzenia świata - stanowiła imago mundi. Jego budowa odbywała się więc zgodnie z przyjętym wcześniej scenariuszem, a sam proces najprawdopodobniej podlegał określonym wymogom rytualnym. Zjawisko takie rozpoznano i dokładnie opisano w wypadku kurhanów epoki brązu w kulturze łużyckiej. Najprawdopodobniej jednak był to długotrwały fenomen i sytuacja wyglądała podobnie w kręgu kultur mogiłowych. Według C. Buśko pierwszy etap budowy kurhanu polegał na wydzieleniu i sakralizacji przestrzeni. Odnotowano, że w tym celu palono ognie, o czym świadczą znaleziska spalenizny pod nasypami kurhanów. Kolejnym takim zabiegiem było zaoranie terenu. Etap drugi stanowiła budowa komory grobowej i nasypu kurhanu. Działania te prawdopodobnie rozpoczynały się dokładnym wytyczeniem granicy konstrukcji. Etap trzeci natomiast to złożenie do grobu zmarłego, co stanowiło zamknięcie całej procedury (Buśko 1993, 86-87). Ze względu na konsekwentną powtarzalność formy jasne jest, że wszystkie czynności również były poddane ścisłym rygorom rytualnym. Tak więc udział $\mathrm{w}$ budowie kurhanu i ceremonii pogrzebowej miał charakter dydaktyczno-formatywny. Pokazywał porządek świata oraz miejsce poszczególnych jednostek w strukturze społecznej. Doświadczenie takie było odczuwane poprzez wiele zmysłów. Istotna była oczywiście bardzo efektowna strona wizualna, ale przeżywano i zapamiętywano również trud wznoszenia takich grobowców.

Kultura łużycka w epoce brązu to czas odejścia od grobów kurhanowych na rzecz płaskich. Ogromne cmentarzyska - pola popielnicowe, stają się charakterystycznym elementem dla tego okresu. Nowa kultura to także zmiana ideologiczna, a wskazuje na nią przede wszystkim nowy sposób traktowania zmarłych. W dotychczasowych badaniach nad obrządkiem ciałopalnym skupiono się na geograficznej genezie tego zwyczaju oraz jego konotacjach religijno-ideowych (Cabalska 1967; 1972; Gediga 1976, 87-96; Gumiński 1980; Szafrański 1987, 144-148). Nie będzie odkryciem stwierdzenie, że centralnym punktem tego rytuału jest zastosowanie ognia. W związku z tym to wartości i znaczenia, które ze sobą niósł, stanowily istotę tego obrządku. W Europie Środkowej pojawił się w neolicie (Wiślański 1979a, 255, ryc. 146: 8; 1979b 293; Kulczycka-Leciejewiczowa 1979, 93, 161) wraz pierwszymi przedmiotami metalowymi. Ta zbieżność wydaje się nie być przypadkowa. Według hymnów Rigwedy ogień to część kompleksu znaczeniowego obejmującego blask fenomenów niebieskich (głównie Słońca) oraz sławę i władzę (Jurewicz 2016b, 176-180; patrz też Gralak 2018, 231-232 na temat przejawów tego zjawiska poprzez kulturę materialną). Na zasadzie partycypacji (magii sympatycznej) (patrz Frazer 1962, 37-69; Wygotski 1989, 113-141) można było nabrać takich cech, nosząc błyszczące ozdoby brązowe lub złote. Zgodnie z tą regułą palone ciała stawały się właśnie taką świetlistą substancją. I była to przemiana ostateczna - na zawsze. Zastosowanie ognia pełniło więc taką samą funkcję jak zaopatrywanie pochówków w brązy. W związku $\mathrm{z}$ tym wyposażanie $\mathrm{w}$ przedmioty metalowe stało się niepotrzebne, skoro zmarli i tak nabierali cech słoneczno-ogniowo-metalicznych. Świetliste (palone) ciała prawdopodobnie każdy mógł zobaczyć $\mathrm{w}$ trakcie pogrzebu. To bardzo widowiskowy show - a sam proces nie pozostawiał wątpliwości co do losów zmarłego. Dodatkowo według opisu Homera, palenie ciała Patroklosa odbywało się w nocy (Il. XXIII 217-232). Podobne zwyczaje odnotowano także u Hetytów (Popko 1980, 182). Taki dobór pory wyraźnie potęgował wrażenia wizualne i emocjonalne. Ponadto dym ze stosu pogrzebowego unosił się do góry. W ten sposób wyraźnie wskazywał sferę niebieską zdominowaną przez światła solarno-astralne. Inspiracją do wprowadzenia takich rytuałów może być też przebieg procesów metalurgicznych (Mierzwiński 2010). Analiza słownictwa indoeuropejskiego wskazuje także, że umiejętności techniczne znane metalurgom były również bardzo przydatne $\mathrm{w}$ trakcie procesu kremacji ciał (A. P. Kowalski 2014, 249-254). W trakcie przetapiania, w wyniku działania ognia, fragmenty surowca bądź przedmioty zmieniają formę. Może 
to być jeden z czynników budujących koncepcję duszy niezwiązanej $\mathrm{z}$ ciałem. Na istnienie takich przekonań wskazują także wybijane od środka dziurki w urnach (Gediga 1976, 164-165; Mierzwiński 2012b, 66-67). Można je interpretować jako otworki na duszę - fenomen występujący w wielu kulturach (patrz Graslund 1994). Sama urna również niesie ze sobą znaczenia - zupełnie zresztą odmienne niż ciałopalenie. Wydaje się, że jest to kontynuacja tradycji znanych wcześniej pochówków w pitosach. Prawdopodobnie odnosiły się do zespołu znaczeń o genezie neolitycznej dotyczących płodności ziemi. Stąd jako urny stosowano naczynia ceramiczne (wykonane z gliny) i dlatego też były one zakopywane. Tak więc wartości niesione przez obrządek ciałopalny wizualizowano poprzez sam proces - zastosowanie ognia, oraz poprzez rekwizyty - ceramiczne urny.

W wypadku pól popielnicowych naczynia stanowią najczęściej spotykany element wyposażenia pochówków. W grobach oprócz urny deponowano także kolejne naczynia, tzw. przystawki. Mogło być ich nawet kilkadziesiąt sztuk (Buśko 1987), wymowny przykład stanowi cmentarzysko w Domasławiu pod Wrocławiem (patrz Gediga, Józefowska 2018; 2019). Sugeruje to silne pozytywne wartościowanie ceramiki i wszelkich czynności z nią związanych. Wydaje się, że chodzi przede wszystkim o konsumpcję i dostęp do dóbr spożywczych. Wskazuje się także, że same obrzędy pogrzebowe były połączone z rozbudowanymi biesiadami, często mającymi charakter ofiar (Gediga 1976, 127-128; patrz też Mierzwiński 2012b - tam dalsza literatura). Znane są również depozyty naczyń - pojedyncze lub gromadne (Horst 1977; Czyborra 1997). Zjawisko to można interpretować jako przejaw admiracji dla płodności. Domniemane rytuały wspólnej konsumpcji operujące bogatym zestawem naczyń (rekwizytów) mogły mieć rozbudowaną stronę wizualną i tworzyć rodzaj narracji. Poprzez zapachy i smaki oddziaływały na kolejne zmysły. Najprawdopodobniej libacje odbywały się zgodnie z obrzędowym scenariuszem - do ich przeprowadzenia potrzebne więc były określone umiejętności i wiedza (kompetencje społeczne)*. Wydaje się także, że

* Do połowy XX w. w Europie Wschodniej umiejętność jedzenia nożem i widelcem nie była dostępna dla wszystkich. Jej brak jednoznacznie stygmatyzował człowieka jako ,niekulturalnego”. celebracja wspólnej konsumpcji wyraża zasadnicze wartości społeczeństw tradycyjnych. Doskonale ujął to R. Kapuściński:

W Afryce kontakt międzyludzki jest wartościa podstawowa. Afrykanin nie umiatby żyć sam. $\mathrm{Na}-$ wet gdyby mógt sam przetrwać materialnie, czułby się skreślony, wyrzucony, zdegradowany. Życie społeczne, zbiorowe nadaje range jego własnej osobowości. To człowiek zanurzony $w$ społeczeństwie, małym, większym (Kapuściński 1999).

Wydaje się, że to jednak przede wszystkim ogień był tym najbardziej spektakularnym elementem obrzędów pogrzebowych. Był bardzo atrakcyjny wizualnie i wydaje się, że była to jedna z przyczyn popularności różnego rodzaju rytuałów dokonywanych przy jego zastosowaniu. Rozumienie procesu ciałopalenia jako swego rodzaju sakralizacji poprzez kontakt z ogniem potwierdzają także źródła pisane. Tak bowiem interpretować można wielokrotnie opisaną w Biblii ofiarę całopalną:

Kapłani, synowie Aarona, przyniosa ogień na ołtarz i ułoża drwa na ogniu. Potem kapłani, synowie Aarona, ułoża części wraz z głowa i tłuszczem na drwach lezacych na ogniu, na oltarzu. Wnętrzności i nogi zwierzęcia będa obmyte woda. Kapłan zamieni to wszystko w dym na oltarzu. To jest catopalenie, ofiara spalana, mita woń dla Pana.

Księga Kapłańska, 1, 7-9.

Co istotne, w procesie tym zwracano uwagę na rolę dymu - to również bardzo atrakcyjny wizualnie element. Można go traktować jako transmitera - unosił się z ziemi do nieba, a wraz z nim także odpowiednie treści:

Oto prawo odnoszace się do ofiary pokarmowej: synowie Aarona przyniosa ja przed Pana przed ołtarz. Potem wezma z niej garść najczystszej maki, należacej do ofiary pokarmowej, wraz z oliwa jej i z calym kadzidtem, które sa na tej ofierze, i zamienia to $\boldsymbol{w}$ dym na ottarzu jako mita woń, jako pamiątkę dla Pana. Księga Kapłańska, 6, 7-8.

Informacje te wskazują, że ogień był traktowany jako rodzaj mediatora. $\mathrm{W}$ ten sposób następowała komunikacja ze sferą sakralną. Zjawiska te łączą się również z rytuałami rozpalania ognia - które częściowo są uchwytne archeologicznie. Stanowią je głazy tzw. miseczkowate, tj. zaopatrzone w otworki średnicy od kilku do kilkunastu centymetrów, będące śladami niecenia ognia przy 
pomocy drewnianego świdra (Almgren 1934, 206207; Szafrański 1974, 373). Na terenie Polski odnotowano kilkadziesiąt takich obiektów (Baruch 1907; Gralak 1998), większość z nich została jednak zniszczona. Cztery takie eratyki znaleziono w Wichowie, pow. żagański (Geschwendt 1939a, 1939b, 1944). Znajdowały się na terenie cmentarzyska kurhanowego kultury łużyckiej z IV okresu epoki brązu (Malinowski 1961, 336), co pozwala określić ich chronologię.

Zagłębienia takie jak na opisywanych głazach są szeroko znane w Europie (ryc. 4: E, F). Szczególnie często występują w Skandynawii i w północnych Niemczech (Almgren 1934, 237-247; Broendstedt
1962, 126-128; Capelle 1972, 1984). Świdry ogniowe znane są natomiast ze źródeł pisanych w Indiach wedyjskich (Witort 1906, 14) i w Grecji starożytnej (Graves 1974, 78). Urządzenie takie wyobrażone jest na ścianie grobowca z Kivik w Szwecji (ryc. 4: A) (Bing 1915, 66; Goldhahn 2009, ryc. 3: 8) z II okresu epoki brązu. Kolejne znane są $\mathrm{z}$ powstałych $\mathrm{w}$ epoce brązu skandynawskich i alpejskich rytów naskalnych (ryc. 4: B-C) (Almgren 1934, 148-149). W Kivik przedstawiono świder w trakcie użytkowania. Dzięki wyobrażonym obok niego postaciom ludzkim, można w przybliżeniu określić jego wielkość. Był to 1,5 do 2 m wysokości pal, na górze zwieńczony prostopadle umiesz-
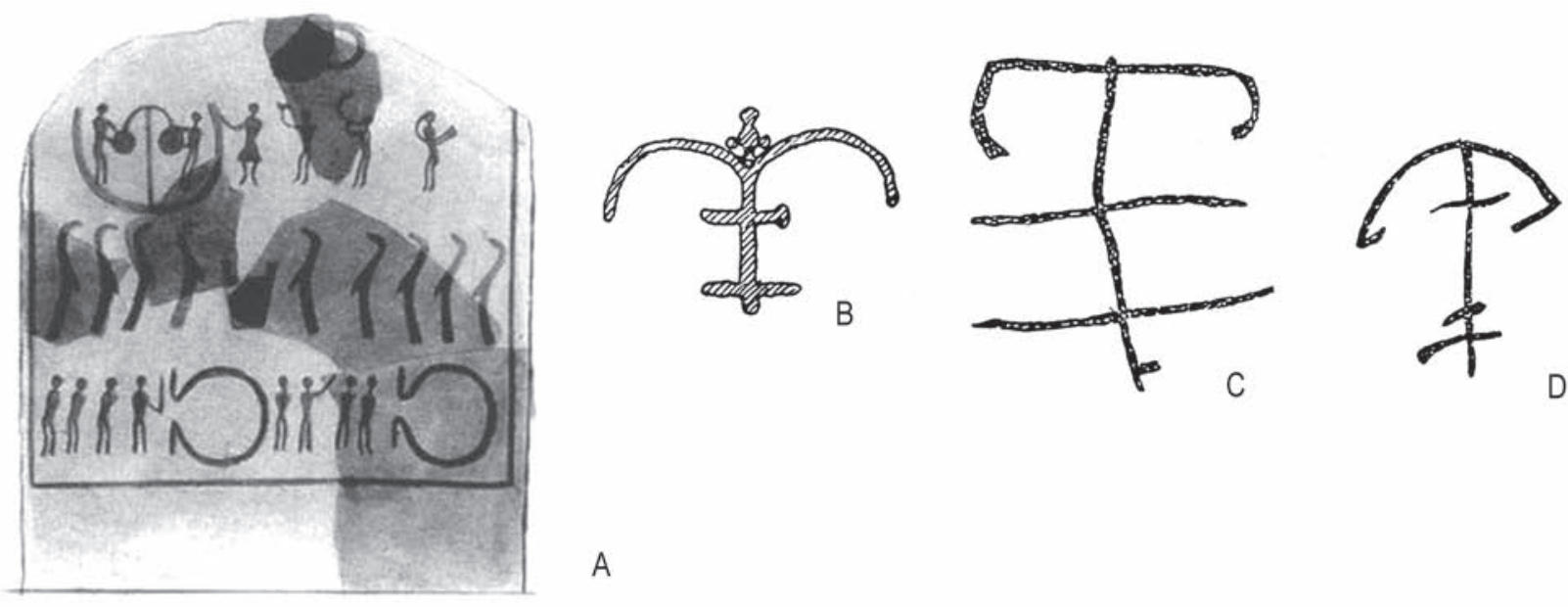

A
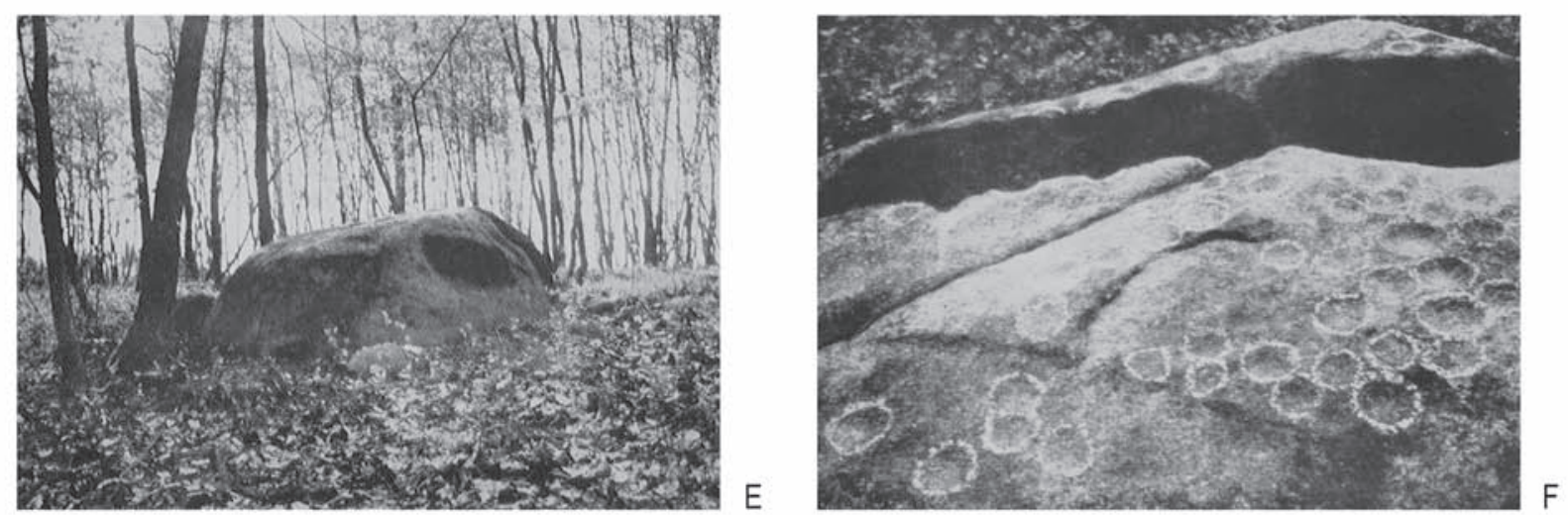

Ryc. 4. Przedstawienia świdra ogniowego: A - Kivik, Szwecja - wyobrażenie na płycie komory grobowej; B - Tanum, Szwecja, ryt naskalny; C-D - Alpy Liguryjskie, Włochy, ryty naskalne. Wichów, pow. żagański:

E - widok głazu; F - ślady niecenia ognia zlokalizowane na górnej powierzchni. A wg Goldhahn 2009, ryc. 3: 8, B-D wg Almgren 1934, ryc. 97-98, E-F wg Geschwendt 1939b, ryc. 3, 4

Fig. 4. Depictions of a fire drill: A - Kivik, Sweden - depiction on the plate of the burial chamber; B - Tanum, Sweden, rock carvings; C-D - Ligurian Alps, Italy, rock carvings. Wichów, Żagań district: E - boulder; F - traces of lighting fire located on the upper surface. A after Goldhahn 2009, fig. 3: 8, B-D after Almgren 1934, fig. 97-98, 
czonymi, zwisającymi obciążnikami, które wirując nadawały mu stateczność. Widać również, że podczas niecenia ognia urządzenie to było wprawiane w ruch przez dwie osoby. Nieco inaczej wyglądają świdry na rytach naskalnych w Alpach. Były to pionowe pale $\mathrm{z}$ dwoma lub trzema poprzeczkami, zwieńczone prostopadłą zagiętą na bokach dużą belką. Poprzeczki służyły prawdopodobnie do trzymania świdra podczas pracy, natomiast prostopadła wieńcząca belka nadawała stateczności. Przyrząd ten, a zwłaszcza jego pionowa wiercąca część, prawdopodobnie był wykonany z leszczynowych lub dębowych lasek. Wskazują na to tradycje niecenia ognia tymi właśnie gatunkami drzewa (Matusiak 1908, 44; A. S. 1900, 143). Zastosowanie urządzenia wielkości człowieka, które w trakcie rotacji powoduje zapłon, także stanowiło rodzaj spektaklu. Był też jasno określony scenariusz - ruch wirowy miał zakończyć się powstaniem płomienia. Tak więc nie był to czysto pragmatyczny akt uzyskania ognia, co przecież można osiągnąć w dużo prostszy sposób. Działanie to miało być widoczne. Świder natomiast można traktować jak rekwizyt o bardzo „teatralnym” charakterze.

Lokalizacja znalezisk z Polski oraz scena z grobowca z Kivik wyraźnie sugerują związek między świdrem ogniowym i obrządkiem pogrzebowym. Rozniecane w ten sposób płomienie mogły służyć do podpalenia stosu ze zmarłym. Zapewne działania takie były wielokrotnie powtarzane - w związku z tym obserwowane dziś zagłębienia mogły powstawać przez wiele lat. W przypadku obiektów znajdowanych poza cmentarzyskami można domniemywać innego przeznaczenia. $Z$ analogii etnograficznych wynika, że niecenie ognia było bardzo ważnym elementem tzw. świąt ogniowych związanych z cyklem rocznym (Frazer 1962, 476-495). Do XIX w. w Polsce w czasie świąt wielkanocnych rozpalano nowy ogień, który potem roznoszono do wszystkich domostw (Klimaszewska 1981, 138). Dokładny opis uzyskiwania takiego ognia w tradycji Hucułów przedstawił S. Vincenz:

Tylko raz do roku i tylko na połoninie rozpala się watrę żywa. Dawniej zapalano ja także w chacie, w Wielki Czwartek zwany Żywnym, i przechowywano ogień aż do wyruszenia w połoniny. Żywej watry na połoninie nie roznieca się ani krzesiwem, ani też zapatkami siarkowymi, lecz innym prastarym sposobem. Oto bierze się suche okragłe drewienko i na jednym końcu rozkuwa się je na krzyż. W tę szpare wsuwa się hubkę i tymże końcem zaktada się po- lanko w okragty ciasny otwór z boku pionowej kło$d y$, tkwiacej w ziemi. Drugi koniec polanka wktada się w jamkę deszczulki, która się je podtrzymuje, po to, aby ciasno obracało się w kłodzie. Następni polanko owija się mocnym powrozem, a dwóch ludzi ujmujac oba końce powrozu, wprawia polanko w ruch wirujacy, aż się zajmie (Vincenz 2002, 18).

W Skandynawii i w wielu krajach europejskich popularne było palenie ogni w czasie przesilenia letniego (Kalif 2007, 164). Liczne zapisy etnograficzne opisują niecenie tzw. żywego ognia - uzyskanego zgodnie z określonym rytuałem. Ogień uzyskany w wyniku działania świdra w Skandynawii określany był natomiast jako rubbing fire lub twisting fire (Kalif 2007, 183). Nowy ogień rozpalano także przed rozpoczęciem wojny oraz w celu zmiany niekorzystnej sytuacji, np. odegnania zarazy, głodu, suszy, nadmiernych deszczy itd. (Matusiak 1908, 44). Najprawdopodobniej z podobnymi rytuałami należy się liczyć w epoce brązu. Warto też dodać, że w religii wedyjskiej rozpalanie nowego ognia - w tym też przy pomocy świdra - jest nieodłączną częścią składową ofiary całopalnej (Jurewicz 2016a, 265-267). W ten sposób można tłumaczyć bardzo liczne występowanie śladów niecenia ognia wśród petroglifów w Skandynawii oraz na różnego rodzaju głazach na kontynencie.

W Indiach wedyjskich świder był atrybutem boga Agniego (Witort 1906, 14; Kalif 2007, 71). Natomiast wzniecony ogień był uznawany za jego bezpośrednią hierofanię (Eliade 1997, 135-137). Imię tego bóstwa jednoznacznie łączy się z ogniem. Co wyraźnie czytelne jest w innych językach indoeuropejskich: łacińskie - ignis; litewskie: ugnis; polskie: ogień (Kalif 2007, 71). Co charakterystyczne, w Indiach uważano, że to właśnie on jest twórcą złota (Rivers 1999, 50, 53), z którego zresztą zbudowane było jego ciało (Eliade 1997, 136, RV IV, 3,1 i X, 20,9). Przekonanie to potwierdza przedstawione powyżej przypuszczenie, że palenie zmarłych lub zdobienie ich przedmiotami metalowymi niosło ze sobą bardzo podobne znaczenia. Rigweda operuje także terminem pomagającym zrozumieć postrzeganie ognia. Sanskryckie określenie tapas oznacza światło i ciepło (słońca i ognia) oraz stan po wypiciu rytualnego napoju odurzającego - somy (Jurewicz 2010, 292; 2016b, 26, 126, 209, 219, 235, 282). Według W. Kaelbera słowo to opisuje także proces niszczenia i konsumowania poprzez 
ciepło/gorąc, w ten sposób określa się także zadawanie ran. Przede wszystkim jest to sposób działania Agniego - poprzez ogień ofiarny. Tapas ma więc również charakter kreatywny - powoduje sakralizację ofiary - jej bezpośredni kontakt ze sferą niebiańską. Dokładnie ten proces miał zachodzić w trakcie palenia ciał zmarłych (Kaelber 1979, 192194).

Warto w tym miejscu zwrócić uwagę na sam sposób rozumienia ofiary czy rytuału. To nie tylko rodzaj prośby na zasadzie do ut des (daję, aby otrzymać). Działalność człowieka na ziemi stanowi powtórzenie czy naśladowanie sposobu funkcjonowania całego świata. To właściwie to samo - w ten sposób manifestuje się jego mikro- i makrokosmiczny wymiar. Ofiara całopalna oraz kremacja zwłok to po prostu wyraz uczestnictwa w theatrum mundi. W ten sposób człowiek lub wspólnota ujawniają swoją obecność. Stanowi to rodzaj wypowiedzi (przy użyciu słów, gestów i działań), przez którą budują swoją tożsamość i określają swoje miejsce w świecie. Bardzo sugestywnie pokazuje to opisa-
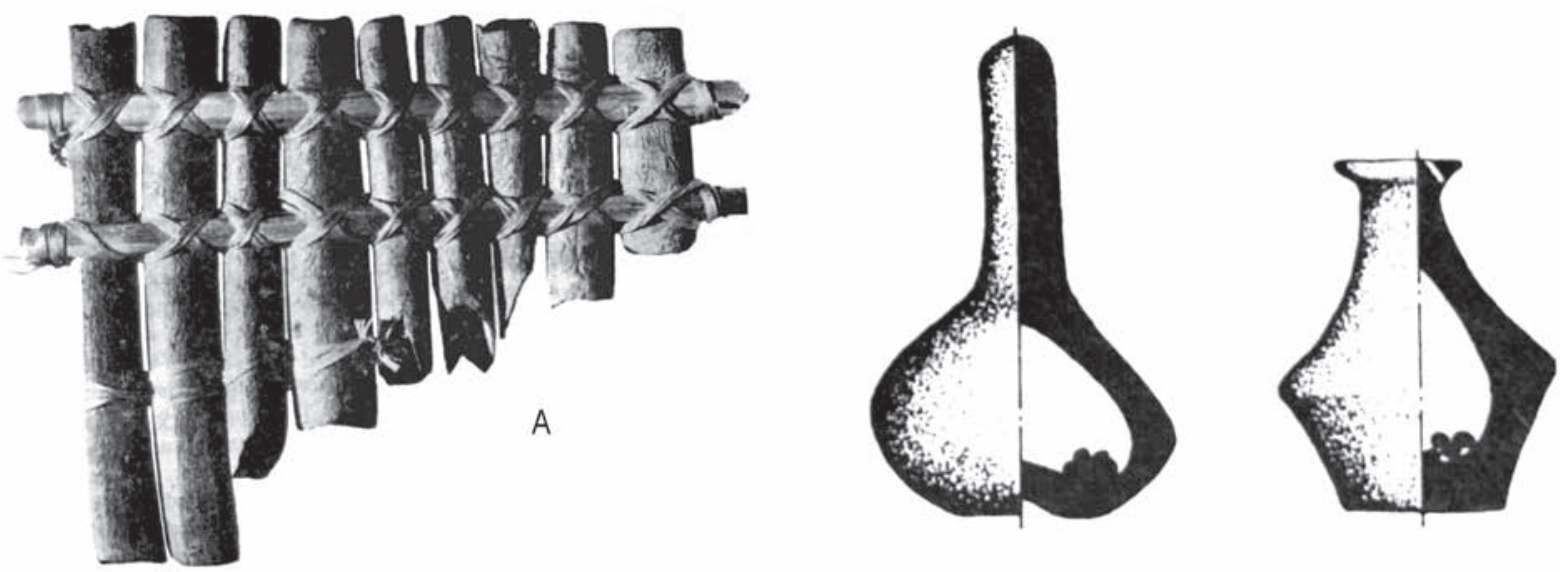

B
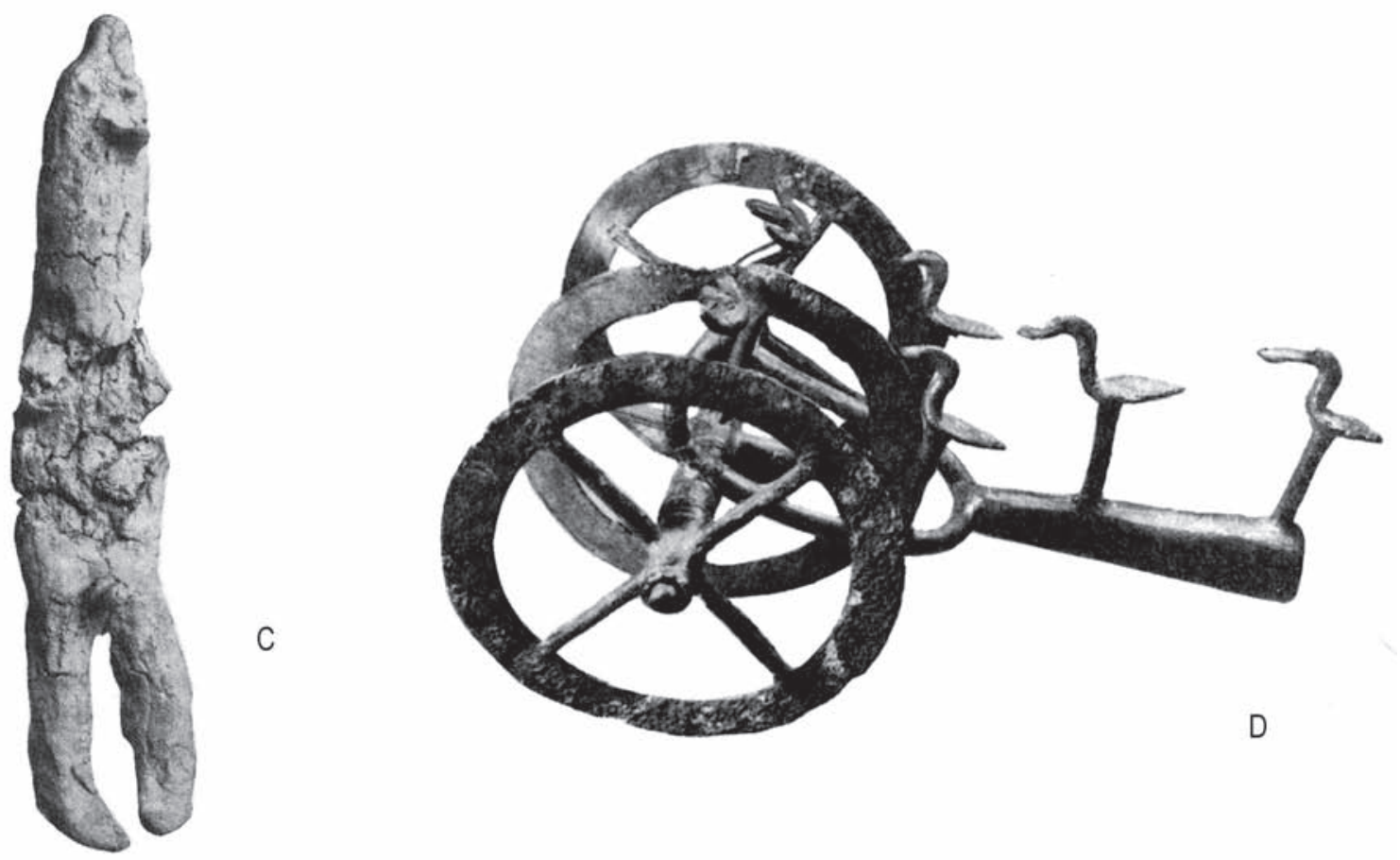

Ryc. 5. A - Przeczyce, pow. będziński, fletnia Pana; B - Danków, pow. kłobucki, grzechotki; C - Gliniany, pow. wołowski, ceramiczna figurka antropomorficzna; D - Kałowice, pow. trzebnicki, tzw. wózek kultowy. A wg Gediga 2006, ryc. 1, B-C-D wg Hensel 1988, ryc. 208, 210, 211

Fig. 5. A - Przeczyce, Będzin district, the flute of Pan; B - Danków, Kłobuck district, rattles; C - Gliniany, Wołów district, ceramic anthropomorfic figurine; D - Kałowice, Trzebnica district, so-called cult wagon. $A$ after Gediga 2006, fig. 1, B-C-D after Hensel 1988, fig. 208, 210, 211 

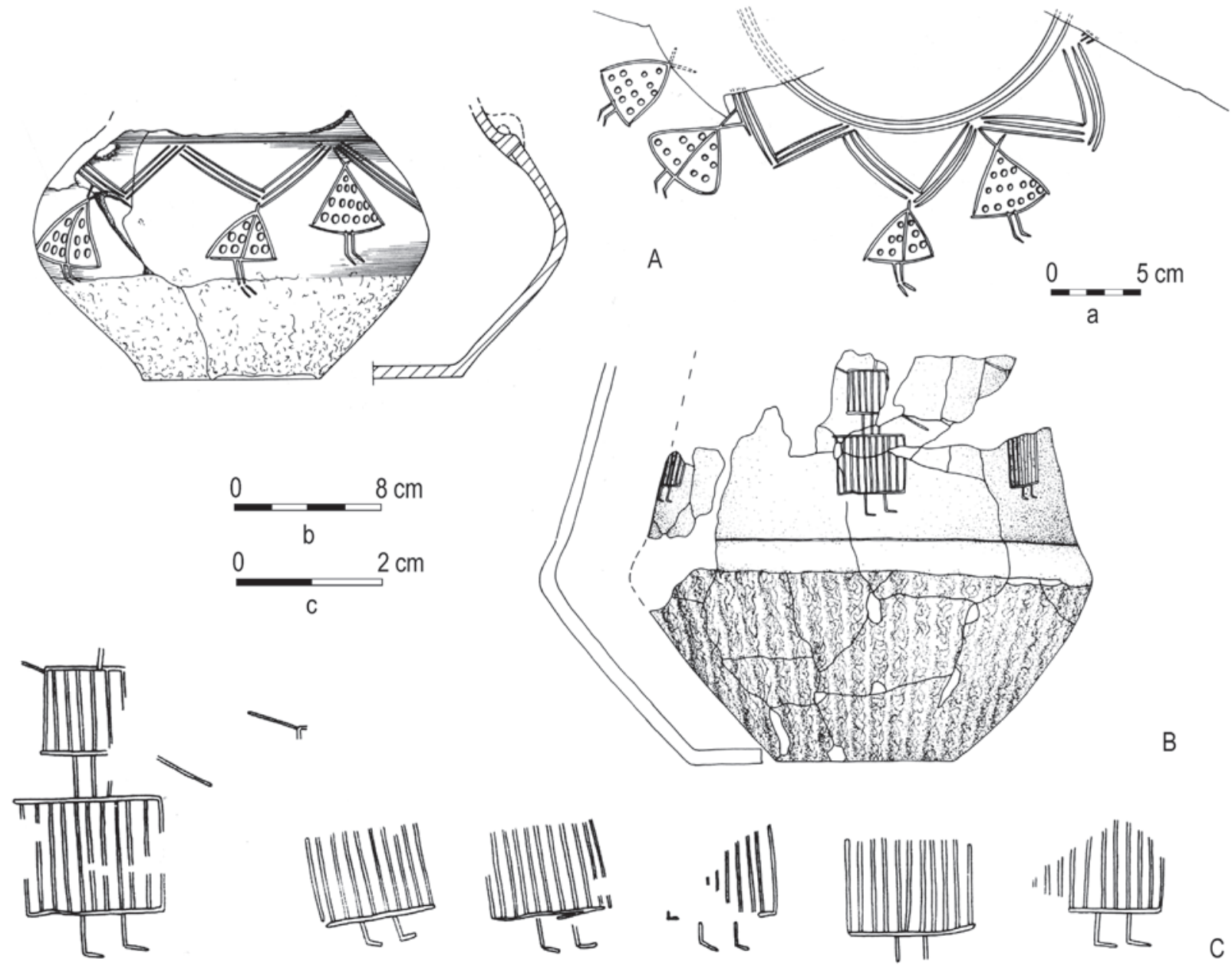

Ryc. 6. Przedstawienia tańca (?) na naczyniach ceramicznych: A - Wenecja Górna, pow. żniński; B-C - Tresta Rządowa, pow. tomaszowski. A wg Zajączkowski 2000, ryc. 3; B-Cwg Oleszczak, Twardowski 2011, Tabl. 40, c, d Fig. 6. Depictions of dancing (?) on ceramic vessels: A - Wenecja Górna, Żnin district; B-C - Tresta Rządowa, Tomaszów district. A after Zajaczkowski 2000, fig. 3; B-C after Oleszczak, Twardowski 2011, Table 40, c, d

na w literaturze wedyjskiej agnihotra. Odprawiano ją każdego dnia podczas wschodu i zachodu Słońca. Polegała na złożeniu do ognia ofiary z mleka lub masła (Eliade 1997, 142; Jurewicz 2016b, 311, 320-321, 517-519). To bardzo proste performatywne działanie pokazywało, że codzienna ludzka egzystencja wpisuje się światowy porządek.

Zestaw znalezisk z późnej epoki brązu wskazuje, że był to okres swego rodzaju eksplozji aktywności artystycznej. Zjawisko to przejawiało się poprzez różne media. Wydaje się, że proces ten można łączyć z przełamaniem tabu na przedstawienia figuralne. Zauważono, że w tego rodzaju sytuacjach poziom ekspresji artystycznej wzrasta również na innych polach (patrz Goody 1997). W wypadku ludności kultury łużyckiej pojawiają się instru- menty muzyczne - grzechotki (ryc. 5: B) (Nowiński 2000) oraz fletnia Pana (ryc. 5: A), ewentualnie też i inne (patrz też Gediga 2006; Pomberger 2016; Schmeiduch 2016). Z terenów naddunajskich znane są także znaleziska masek ceramicznych (Hrala, Špaček 2001) oraz wykonanych z ludzkich czaszek (Furmánek, Veliačik, Vladár 1991, 293, ryc. 39). Pojawiają się też ceramiczne reprezentacje ludzi i zwierząt (patrz Gediga 1970). Figurka określana jako „Apollo z Glinian” (Hensel 1988, 323 , ryc. 209) prawdopodobnie przedstawia mężczyznę w masce $\mathrm{z}$ ptasim dziobem oraz $\mathrm{z}$ fallusem we wzwodzie (ryc. 5: C). Nie można wykluczyć, że jest to reprezentacja człowieka odgrywającego scenę rytualną. Przedstawienia ludzi przebranych za ptaki - noszących skrzydła i maski z długimi dzio- 
bami - znane są również z rytów skandynawskich (Coles 1995, ryc. 10.2: f, 10.3: g; Skogstrand 2006, 96 , ryc. 20).

Prawdopodobnie również tzw. wózki kultowe wykorzystywano jako rekwizyty w trakcie działań parateatralnych. Przedmioty te to zazwyczaj wykonane $\mathrm{z}$ brązu miniatury wozów z trzema czteroszprychowymi kołami (ryc. 5: D). Dodatkowo umieszczano na nich wyobrażenia ptaków wodnych lub głowy zwierzęce zaopatrzone w półkoliste rogi. Zapewne to one miały ciągnąc wyobrażane wozy. Przedstawienia takie interpretować można jako wizualizację mitu mówiącego o poruszaniu się słońca po nieboskłonie - właśnie w wozie zaprzężonym w ptaki. Co charakterystyczne, wózki takie posiadały pustą tuleję, w którą najprawdopodobniej wkładano drewniane uchwyty (po prostu kije) (patrz Gediga 1976, 173-174). Brak danych, by określić ich długość. Przedmioty takie mogły więc być przesuwane po ziemi lub unoszone w powietrzu. Sama ich budowa świadczy więc, że były używane do odgrywania sposobu poruszania się mitycznego wozu niosącego Słońce.

U schyłku epoki brązu, a zwłaszcza w okresie halsztackim, na naczyniach ceramicznych zaczynają się pojawiać postacie ludzkie tworzące sceny narracyjne (Gediga 1976, 102, ryc. 12). Wskazuje się, że rozmieszczone równomiernie dookoła naczynia mogą wyobrażać taniec (Grossman, Popławska 2018), w tym taniec w koło (Hensel 1988, 314, ryc. 198). Przedstawienia takie (ryc. 6: A, B) znane są m.in. z Tresty Rządowej, pow. tomaszowski (Oleszczak, Twardowski 2011, tabl. 40, c, d) czy z Wenecji, pow. żniński (Zajączkowski 2000, fig. 3). Sceny narracyjne pojawiają się też na urnach ludności kultury pomorskiej. Wskazuje się, że mogą one wyobrażać ceremonie pogrzebowe - także z zastosowaniem wozów (patrz Kwapiński 1993). W kulturze tej bardzo licznie występują również urny z przedstawieniami twarzy. Wskazuje się, że przedmioty te $\mathrm{w}$ rytuale pogrzebowym mogły pełnić funkcję analogiczną do rekwizytów teatralnych (Kowalska 2003). Wszystkie te fenomeny stanowią jednak przejaw kultury charakterystycznej już dla wczesnej epoki żelaza.

Podsumowując można założyć, że duża część życia społecznego ludności epoki brązu opierała się na mniej lub bardziej zrytualizowanych, performatywnych i parateatralnych działaniach. Często gra społeczna (akcja) rozgrywała się w określonej i specjalnie przygotowanej scenografii. Tak bowiem można widzieć przestrzeń cmentarzysk. Osoba społeczna była natomiast konstruowana przy pomocy charakteryzacji, rekwizytów, scenografii oraz zrytualizowanych zachowań. To te elementy tworzyły jej uczestników - aktorów. To w ten sposób przekazywano komunikaty i wartości oraz przekonania religijne. W tym sensie działania parateatralne w ówczesnym społeczeństwie stanowiły przestrzeń dla zabawy oraz wspólnego wielozmysłowego doświadczania zdarzeń i znaczeń. Był to też oczywiście rodzaj socjalizacji i kontroli - uczestników zmuszano do określonego postępowania i narzucano im sposób rozumienia świata.

Taki rodzaj aktywności parateatralnej oraz jej rozumienia przetrwał (przynajmniej częściowo) do $\mathrm{XX}$ wieku w folklorze europejskim. Oczywiście ze względu na przemiany ideologiczne zmienił się przekaz - ale sam sposób działania miał zdecydowanie bardziej uniwersalny charakter. Wydaje się więc, że opis dotyczący niedawno jeszcze funkcjonujących społeczności tradycyjnych w Polsce może dać wyobrażenie o formacji umysłowej typowej dla epoki brązu:

Realizacja obrzędu konstytuowała sytuacje jakościowo odmienna od sytuacji codziennych. Najlepiej wyraża się to $w$ wypadkach, gdy obrzęd jest odtworzeniem mitu, gdy jest widowiskiem, do którego scenariusza dostarczaja wydarzenia mityczne. Wówczas bowiem reaktualizowana jest rzeczywistość mityczna. Aktorzy wcielaja się w postacie bohaterów, bogów, istot mitycznych, dokonują czynów boskich, maja możność wptywania na bieg wydarzeń $w$ świecie, regulowania wedtug własnej woli zjawisk naturalnych. W odczuciach społeczności chtopskich obrzęd nie byt widowiskiem, odpowiednikiem teatru, a więc czymśs sztucznym, lecz autentycznym dokonywaniem sie mitu w konkretnym miejscu i czasie (Tomiccy J. R. 1975, 152).

Rekapitulując, nakreślona powyżej perspektywa badawcza pozwala na inny sposób interpretacji wielu rodzajów znalezisk archeologicznych. Przede wszystkim zaczynają się one przedstawiać jako wytwory mające na celu komunikację. Niosą informacje, które możliwe są do odczytania również i dziś. 


\section{ON PARATHEATRICAL ACTIVITIES IN THE BRONZE AGE}

The character of information on the culture of past societies that is provided by archaeological finds depends on the questions posed by their discoverers. That is why every different research perspective considerably extends our knowledge. Of course, issues related to the theater in the prehistory of Central Europe do not belong to the set of obvious questions posed by archaeologists. Nevertheless, this kind of artistic expression (and way of communication) can be observed in all human societies. We can say it is a constant and immanent part of human culture. The body, along with products of material culture, has been a medium used during different kinds of rituals. Dances, chants, group consumption, funeral ceremonies - they often have a "paratheatrical" character (Peterson Royse 2010, 247-268). This term, just like Theater of Sources, was introduced in the 1970s by J. Grotowski (1979, 94-103). Initially, it concerned off-stage theatrical activities (paratheater), but later the presence of similar phenomena was noticed in traditional religious rituals (theater of sources). The issue has become a subject of separate studies (see: Kocur 2013). Presently, those ritual acts that are focused on expression and should have an impact on the emotions of the audience are referred to as paratheatrical activity. The presence of spectators is therefore essential. What is more, artistic skills are needed to conduct the rituals - workshop and technique that all performers should have. Such events must not be a random improvisation - they are repetitive, since they result from knowledge and tradition present in a given society. It is also suggested that rituals are implementation of particular myths (Stomma 2008, 166-167) that can be perceived as a kind of screenplay. Activities of a theatrical character resulted also from the way traditional societies functioned. The analysis of Greek archaic poetry and Homer's epics reveal that the personality structure of particular individuals lacks the managing unit - the 'me' (Kowalski 1999, 148-152; Angutek 2003, 61-64). Human existence expressed itself by being perceived by others (Vernant 2000; Segal 2000). People found themselves in the eyes of other people, which made them want to be looked at (Mierzwiński 2012a, 82). Additionally, in many cultures (especially among the Indo-Europeans) to see means to know (A. P. Kowalski 2001, 129-130). Paratheatrical activities were therefore a very catchy communication strategy. This applies particularly to illiterate societies, and so it seems that such rituals must have been common in prehistory. Archaeological finds allow us to investigate them only to some extent, as usually it is possible to explore only the last - final scene, i.e., the moment when the artefacts were deposited in the ground. It can be compared to the moment when actors are on stage and the curtain falls, as the performance is already over. Two criteria were used in order to identify finds as a manifestation of paratheatrical activity. First of all, they must suggest a repeated action. This proves the presence of people who had appropriate knowledge and skills. Moreover, the finds must confirm that the actions were intended for an audience (spectators). Implicitly, they were supposed to have an impact on their emotions as well. The last issue, however, must remain debatable - emotions refer to all people, but they depend on the culture and mental aptitudes of individuals. It is worth noting that this kind of approach towards ritual activities, despite appearances, is nothing new. The play by Adam Mickiewicz titled Dziady is actually to some extent a transfer of traditional folk rituals to the theater stage (see: Kolankiewicz 1999). It is even more suggestive because the work belongs to the canon of the Polish literature and its character is somehow formative for the whole national culture.

Complex forms of paratheatrical and theatrical activities in the Bronze Age were noted in the Middle East and in the Mediterranean zone. In those regions it was the ruler who was responsible for organizing feasts, offerings, and festivities connected with them. In this way rulers manifested their power. In Egypt celebrations were accompanied by shows performed by musicians, dancers, and acrobats (Marinatos 2009, 33-34). Paratheatrical 
events took place in specially designed scenography. In Minoan Greece, space for theater performances was distinguished in the area of the Palace of Knossos (Rutkowski 1990, 13). Also, numerous depictions of people jumping over bulls are known (Hansen 2015, 151-152, fig. 24-27) - it resembles today's corrida. It is possible that public rituals involving snakes were present as well, which is suggested by the depictions of priestesses holding them (Rutkowski 1990, 16). The throne room from Knossos can be seen as the scenery of paratheatrical activities, too (Ałpatow 1976, 99, fig. 76). Various rituals took place there, which is confirmed by large sacrificial vessels found at the throne. Walls are decorated with frescoes that depict flowers and griffins. Two such depictions flanked the marble throne. Due to the construction and location of the room it could have been lit by the rays of the rising Sun. The aim of the scenography was to emphasize the status of the ruler. What is characteristic is that the concept of the throne room itself and its location has direct analogies in the state of the Hittites (for the description and analysis see: Marinatos 2009, 50-65, fig. 2.23, 4.1, 4.2, 4.3, 4.5). As a place of similar paratheatrical activities, megarons, known in Mycenean culture, can be also perceived (Rutkowski 1990, 29). Building tombs for rulers and funeral ceremonies connected with them may be considered a form of such activity as well. The Egyptian pyramids are probably the most suggestive example. The form of Mycenean tholoi was also complex (see: Schliemann 1878 ).

In the case of Central Europe there are burials that comprise a basic source for the research on paratheatrical activities. In the Late Neolithic and in the beginning of the Bronze Age a very characteristic phenomenon can be noted. The earlier tradition of creating ceramic figurative depictions was abandoned. Artistic expression became almost completely non-figurative. Since there was a taboo, according to which depicting a human figure was forbidden, human ideas, values, and emotions were expressed through a real human body, including a dead one. During a ceremony it became an important prop and an information carrier.

When it comes to the Únětice culture, it has been observed that the dead were placed in graves in specific positions. This phenomenon was noticeable already at the very end of the Neolithic and in the beginnings of the Bronze Age in vast areas of Central and Eastern Europe (fig. 1) (Häusler 1977).
Several repeating positions and gestures expressed through the arrangement of hands were identified. It is the repeatability that suggests the presence of people who knew how to arrange bodies in appropriate positions. This was not accidental. Thus, meanings understandable only for the audience those who attended the funerary ritual - were expressed. It can also be assumed that the death and the funeral itself were parts of a ritual which had a major impact on the emotions.

Apart from arranging bodies of the dead in a specified position, pulling legs up was also an important element of a funerary ritual. This applies to the vast majority of burials. The unnatural position in some cases suggests that they could have been tied (Romanow, 1973, 129-130), or even broken at the joints. It seems that it was one of the most important elements of, nomen omen, rites of passage. This procedure definitely prevented the deceased from walking and therefore returning to the world of the living. Of course, the ritual had a clearly "theatrical" character. The deceased would not be able to walk even if their legs had not been tied and their knees broken. Thus, a ritual was played and messages understandable for the participants of the funeral ceremony were communicated. One can only guess their precise meaning. In Homer's much later works we can find statements indicating that knees were perceived as an essential aspect of vital strength (Mierzwiński 2012a, 30). A man standing firmly on his legs is a visible sign of life and health. A lying man can be interpreted as the opposite - sick or dead.

Another characteristic feature of the funeral rite was the re-opening of graves (Fig. 2: A) (Kadrow 2001, 133-134; Gralak 2007, 197). It seems that one of the aims of this practice was taking out the bones of the buried. The repeatability indicates the presence of people who had the knowledge and skills to do it. However, we do not have any information whether such actions were undertaken publicly, in front of other members of society. If so - they must have evoked strong emotions. Single human bones are also found within homesteads, which means they were probably exposed. It is possible that they appeared in houses as a result of the re-opening of graves. It is clearly visible that human remains were used as props in the social game.

In the case of the Únětice culture also a kind of fascination with the human head was noted. Graves containing skeletons without skulls have been dis- 
covered (Fig. 2: B) (Primas 1977, 33-34; Gralak 2009a). There are no analyses that explain whether the skulls were removed during the opening of graves, or if the person was decapitated before the burial, dead or alive. Burials of skulls alone are also known (Gralak 2009b). It seems this group of phenomena clearly shows that this part of the human body had a special place in the way physicality was perceived at that time. The finds leave no doubt that different rituals, ones in which the human head or skull was an important prop, were performed. Decapitation of either an alive or dead person demonstrated features of paratheatrical activities. They were repeated, required special skills and - just like other burial rituals - were performed in public. Using a head or a skull most probably drove emotions as well. That is why the skull scene from Shakespeare's Hamlet has become an icon of what is presently understood as theater.

The other ritual that bears features of paratheater is fragmentation of the body (Gralak 2007, 169, 190, fig. 60-61, 77-79). In the Únětice culture partial burials are known (Fig. 2: C). In the grave only selected parts of a body, often mixed, were placed. The course of the process itself is not wellrecognized. We can only assume that it was mechanical fragmentation or excarnation. In both cases the process must have been controlled by people who had necessary skills. As a form of burial it was probably done in public and therefore impacted the viewers. As every radical interference with a human body, it stirred vivid emotions. It also seems that the body fragmentation ritual was a reenactment of the myths that functioned there. Similar threads were noted in the Mediterranean zone and they can at least to some extent explain the phenomenon. In the Ugaritic epic about Baal (the god of thunder) there is a description of the fragmentation of his body done by Mot (the ruler of the dead). His remains reached the afterlife thanks to the goddess Shapash. With the help of the goddess Anat he was pieced together and then defeated death (Marinatos 2009, 171). Similar elements appear in the Egyptian myths connected with Osiris. He was to have been a teacher of agriculture. He was killed by his brother Seth and his fragmented body was thrown into the Nile. It was found and pieced together by Isis, which resulted in his resurrection. He became the ruler of the underworld and the judge of the dead. The manifestation of this phenomenon was an annual ritual. On his body, visualized in the form of a mummy wrapped in bandages, crops sprouted and grew (Frazer 1962, 322-336). It is worth noting that the population of the Unětice culture buried the bodies of small children in large vessels (pithoi) used for storing grains. The tradition is of distant - Anatolian - origin (Primas 1977, 81-82; NiesiołowskaWędzka 1980, 34; Szmukier 1980, 11; Gediga 2003, 173). Moreover, querns and grindstones were also found in graves (Woźny 2005, 159-196). It seems then that interfering with dead bodies and bones stems from the Early Neolithic traditions connected with agricultural cults. In general, they are based on reflections that resulted from the observations of the agricultural cycle. The sowing, growing, and dying of crops over a year provoked a similar view on human life and death (see: Eliade 1993, 319-346). Of course it cannot be assumed that members of the Unětice culture were truly familiar with the myths about Baal or Osiris. However, burial rituals that combined body fragmentation as well as fascination with crops suggest that they might have known certain motifs.

Animal offerings can also be deemed paratheatrical activity. It was a kind of show that was supposed to have been watched by a target afterlife spectator. In the Únětice culture in Lower Silesia two types of animal burials were noted: complete (Fig. 2: D) and consumed (Gralak 2011). The first type included only cattle burials that were discovered on both settlements and cemeteries. The positioning of the skeletons oscillated along the north-south axis. With the exception of a burial from Szczepankowice, heads were facing south. It is worth noting that an analogous orientation was recorded in the case of human burials (Sarnowska 1969, 19; Kadrow 2001, 121). Other additional rituals were connected with the head as well, including decapitation in the case of skeletons from Milejowice and Nowa Wieś Wrocławska. They also have their analogies in burials typical of the population of the Únětice culture (Lorencova, Beneš, Podborsky 1987, 140-142). In the case of the burial from Szczepankowice the head was unnaturally arched backwards, which suggests that the animal's neck was broken. Such practices most probably result from religious beliefs that valued this part of the body. In two cases - in Nowa Wieś Wrocławska and Szczepankowice - also some practices connected with limbs, which were presumably tied up, were noted. As was already mentioned, the same practice was recorded in the case of human burials, 
too. Therefore, it can be noticed that there are structural similarities between these types of burials. Skillful killing of an animal (according to a defined ritual) and placing it in a grave required knowledge and skills. The act itself, together with the funeral, was most likely performed in public, which means it was supposed to have an impact on the audience. Apparently, the death of a living creature always evokes strong emotions.

In the settlements in Wojkowice and Nowa Wieś Wrocławska pits containing inentionally deposited animal bones were also recorded - probably consumption leftovers (Gralak 2011, 214-219, fig. 4-6). In those pits the remains of cattle and pigs were found, and they often belonged to young animals. They clearly differ from similar finds from other settlement sites. Those were presumably the remains of the whole body of one animal, deposited in a specially prepared pit. The addition of other bones was marginal or there was no addition at all. It seems that in the case of such deposits most activities were part of a ritual. They were probably the remains of a ritual feast during which animals, offerings for gods at the same time, were consumed. Therefore, they comprised an element of the sacrum, and their remains required a special treatment. Deposits of the remaining bones are also known (Moszyński 1967, 258; Makiewicz 1993, 75; Marciniak 1996, 141; Gralak 2011, 214-221). Consumption of sacrificed animals in the Mediterranean world was justified by mythology. It was one of the gifts of Prometheus who deceived Zeus and left only fat, skins, and bones for the gods (Hezjod, Teogonia, 545; see also: Graves 1974, 144-145). This kind of deposit proves that the practices were determined by a defined ritual, in which the public participated. It was carried out by a group and every participant played their own role. A feast might be therefore regarded as a kind of performance. It is also worth adding that such a ritual, referred to as "the feast of the goat", was mentioned in A. Mickiewicz's Dziady $(1992,13)$.

During the time of the Tumulus culture, nonfigurative artistic expression still prevailed. Just as earlier, a real body was used to express ideas connected with corporality. However, the way it was perceived changed. It is clearly visible that the dead were treated differently, depending on their social status, as from this period almost only mound burials are known (Gediga 1978, 145-146). They probably belonged to the elite (Fig. 3: A-B). Graves of other members of the society remain unknown. In general, the bodies of the deceased had a different status.

Compared to period I of the Bronze Age, there was also a change in funerary rites. The dead were usually laid upright on their back. What is characteristic, all rituals connected with physical interference with the dead's corporality were abandoned. No legs restrained, nor body fragmentation or manipulation with skulls was noticed - and there is no sign of re-opening burial pits. It is therefore evident that attention was focused on retaining the integrity of the body after death. Funerary equipment was also very characteristic. It included bronze items (Gediga 1978, 146) of various kinds, clearly depending on the dead's gender (Gedl 1975, 92). In the case of men those were mostly weapons, and in women's graves - jewellery and accessories (Fig. 3: C-M). The differences between genders were strongly emphasized. It is likely that such relations comprised one of the most important elements of social structure at that time. It seems that large amounts of richly decorated bronze items somehow replaced the earlier traditions that involved manipulations with the remains of the human body.

Generally, culture in period II of the Bronze Age gained a more performative-theatrical character. The social role of members of the elite was played using props (bronze items). Without those items such people actually did not exist, just like the members of lower social classes whose graves remain unknown. Metal objects probably worked as a code that defined the person who was wearing them and determined their place in the social structure. What is characteristic, a similar phenomenon was noted in ancient Greek theater. Items referred to as gnorismanta were used as props. According to Aristotle, they let spectators recognize the character. These were weapons and jewellery - they determined the ancestry of the carrier (Arystoteles, Poetyka 16; Kowalska 2003, 33).

Using metal objects shaped people directly in a physical way. Carrying weapons by men forced a specific posture and movements. Physical exercise connected with the use of weapons helped build the muscles. Thus, they developed a specific way of moving (body language), different from other members of the society. The fact that figurative depictions became forbidden is one of the causes of the explosion of a phenomenon referred to as „warrior's beauty” (see: Treherne 1995). The body 
as a message carrier (that could not have been replaced by anything in many cases) must have been properly decorated and taken care of. From later periods in the Mediterranean region it is known that warriors fought naked. Also, the earliest armour imitated the shape of a human body (Żygulski 1998, 29-31). Heavy metal jewellery in large amounts was, in turn, worn mostly by women. This also forced specific movements. Especially bracelets on legs required a special way of taking steps. Moreover, due to the heavy weight, the movement must have been slower*. There is also one other aspect - bronze items made a metallic sound when they hit each other. A biblical description of a priestly garment suggests that it might have been entirely intentional:

The gold bells and the pomegranates are to alternate around the hem of the robe. Aaron must wear it when he ministers. The sound of the bells will be heard when he enters the Holy Place (... ). Exodus 28: 34-35.

Generally, we can say that bodies were adjusted to the props, not the other way round. Like in the German proverb "Kleider machen Leute" (clothes make people) - these were clothes that created visible and characteristic social figures. It is likely that members of the elite were physically much different from other members of society. They could have been easily recognized - thanks to the glowing bronze items. They moved in a different way, making characteristic sounds. What is important, in Indo-European languages, roots of the words connected with embellishments, clothes, and decorating the body can also be found in terms related to

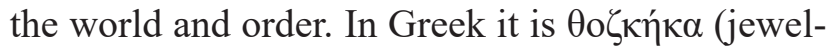

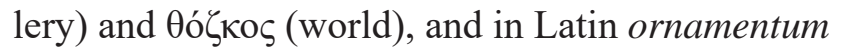

* In the case of the traditional culture of Sub-Saharan Africa it was noted (Herbert 1984, 217, 243) that wearing heavy bracelets on the legs (and not only) since childhood caused a characteristic way of walking. It was defined as duck-like/bovine like encumbered walk. Sometimes it could have been observed in the case chieftains, however, it was most often visible among women. This showed that a person does not have to do any physical work, which explicitly indicated their highest social status. This way of moving was imitated by people who never wore such heavy jewellery. It expressed their high social aspirations. (decoration) and ordo/ordino (world, order) (Chausidis 2017, 933). Thus, decorating bodies, including wearing jewellery, expressed and reflected the way of understanding the universal order.

The funeral ceremony in the Tumulus culture was a complex show. The body (being a kind of fetish), equipped with glowing metal props, must have been visible. It was a visualization of the social status of those who organized the funeral. The show was, in fact, prepared for the living, not for the dead who were not able to see it. Obviously, it is difficult to reconstruct how the ceremony proceeded. What we can say is that it was a performance based on a ritual whose aim was to exclude the deceased from the community of the living. It was a show that was supposed to consolidate the identity of the community after losing one of its members. What is more, such a ceremony was supposed to confirm and legitimize the existing social hierarchy. It is also worth noting that burial mounds, together with the memory of the buried, shaped the space in which the members of the Tumulus culture lived. They were seen from afar and probably served as landmarks.

Erecting a burial mound can also be considered as an extensive show. Just as in the case of a funeral, such actions might have had a strong impact on people's emotions. The erection itself - gathering material and forming a mound etc. - required physical work. Division of labour was also possible. Most probably there were members of the elite who ordered and directed the construction. Carrying this out was the task of other members of society. The whole process clearly showed the hierarchical relations. The mounds were erected by those who would never be buried in them. What is more, they would not have any graves at all.

Other elements are the meanings that a mound itself carried. The structure of such a tomb is a sacred space which has repeating structural elements, identified and described by S. Czarnowski (1963) and M. Eliade (1996, 34-40). Boundaries between the spheres of sacrum and profanum were defined by a surrounding stone ring, or alternatively a groove. The central point was marked by the burial, placed inside a chamber. The whole horizontal structure was located according to cardinal directions or other constant elements of spatial perception (e.g., astronomical). It was expressed through the orientation of the burial pit and the body. In some cases, e.g., in Grabonóg it was additionally emphasized by stone 
lines crossing in the middle (Fig. 3). The vertical structure of those constructions is also characterized by elements in a specified order. Burial chambers were dug in the ground and the mound was built, pointing upwards. It is thus visible that such constructions reflect the division into three spheres - heavenly, earthly, and the underworld. According to the concept of M. Eliade, through the central point of the sphere of sacrum runs the axis mundi, connecting all three levels. Generally, the construction of a burial mound reflected the way the world was perceived at that time - it was the imago mundi. It was built in accordance with an earlier prepared scenario and the process itself was subject to specified ritual requirements. The phenomenon was recognized and precisely described in the case of the Bronze Age burial mounds of the Urnfield culture. Most probably it was a long-lasting phenomenon and the situation was similar in the Tumulus culture. According to C. Buśko, the first stage of building a burial mound involved the delimitation and sacralization of space. It has been noted that in order to do so a fire was lit, which is suggested by the burnt layers found underneath the mounds. Another such procedure was ploughing the land. In the second stage a burial chamber and a mound were built. It probably began with precise demarcation of the construction's border. The third stage was placing the dead in the grave, which closed the whole procedure (Buśko 1993, 86-87). The consistent repetitiveness of the form clearly indicates that all operations were also subject to strict ritual rules. Therefore, taking part in the erection of a burial mound and funeral ceremony had a didactic-formative character. It showed the world order and the place of individuals in the social structure. The experience was perceived through many senses. The visual side was highly impressive, but the effort put into the process of building such tombs was also deeply experienced and remembered.

The period of the Urnfield culture in the Bronze Age was the time when burial mounds were replaced by flat burials. Huge cemeteries, referred to as urnfields, became a characteristic element of the period. The new culture brought also an ideological change, which is indicated by the new way of treating the dead. The research on cremation burials was hitherto focused on the geographic origins of this tradition and its religious and ideological connotations (Cabalska 1967; 1972; Gediga 1976, 87-96; Gumiński 1980; Szafrański 1987, 144-148). It is no surprise that the central point of the ritual was connected with using fire. Thus, values and meanings that it carried were the essence of the rite. In Central Europe it appeared in the Neolithic (Wiślański 1979a, 255, ryc. 146: 8; 1979b, 293; Kulczycka-Leciejewiczowa $1979,93,161)$ together with the first metal objects. This does not seem to be a coincidence. According to the Hymns of the Rig-Veda, fire is part of a meaning complex which embraces the shine of celestial phenomena (mainly the Sun) as well as glory and power (Jurewicz 2016b, 176-180, see also: Gralak 2018, 231-232 for manifestations of this phenomenon in the material culture). By the rule of participation (sympathetic magic) (see: Frazer 1962, 37-69; Wygotski 1989, 113-141) it was possible to gain the features by wearing glowing bronze or gold decoration accessories. According to this rule, burnt bodies became such a glowing substance. And the change was for good. Using fire served the same function as furnishing burial pits with bronze objects. For that reason equipping graves with metal items became unnecessary if the dead gained those sun-fire-metallic features anyway. Glowing (burning) bodies could have been seen by anyone during the funeral. It was a very spectacular show - and the process itself left no doubts regarding the fate of the deceased. Additionally, according to Homer's description, the body of Patroclus was burnt during the night (Il. XXIII 217-232). Similar traditions were noted among the Hittites as well (Popko 1980, 182). Such a choice regarding the time of day visibly enhanced visual and emotional impressions. What is more, the smoke from the funeral pyre went up and therefore pointed out clearly to the heavenly sphere dominated by solar and astral lights. The inspiration to introduce such rituals could have been the metallurgical process (Mierzwiński 2010). The analysis of Indo-European vocabulary reveals that technical skills possessed by metallurgists were also very useful during the cremation of bodies (A. P. Kowalski 2014, 249-254). While melting, fragments of the raw material change their form in fire. This can be one of the factors that build the concept of a soul not connected with a body. The existence of such beliefs is indicated by the presence of holes knocked out from the inner side of urns (Gediga 1976, 164-165; Mierzwiński 2012b, 66-67). They can be interpreted as holes for the soul - a phenomenon known in various cultures (see: Graslund 1994). The urn itself also carries a wealth of meanings, ones completely different than those 
in the case of cremation. It seems that it is the continuation of the traditions known from the earlier pithos burials. It probably referred to the complex of meanings of Neolithic origin regarding the land's fertility. That is why ceramic vessels (made of clay) were used as urns and for the same reason they were buried in the ground. Thus, the values carried by the cremation ritual were visualized by the process itself - using fire, as well as props - ceramic urns.

In the case of urnfields, vessels are the most common elements of grave furnishings. Apart from the urn, further vessels were also deposited in graves. There could have been even as many as a few dozens of them (Buśko 1987). The cemetery in Domasław near Wrocław is a meaningful example (see: Gediga, Józefowska 2018, 2019). This suggests a strong positive evaluation of ceramics and all activities connected with it. It seems that it is connected mainly with consumption and the access to food. It has been stated that funerary rites were connected with lavish feasts, which often had the character of offerings (Gediga 1976, 127-128; see also: Mierzwiński 2012b with further literature). Vessel deposits are also known, both single and group ones (Horst 1977; Czyborra 1997). The phenomenon can be interpreted as a manifestation of admiration for fertility. The hypothetical rituals based on eating together, involving an extensive set of vessels (props) could have been characterized by a complex visual side and therefore created a kind of narration. Through scents and tastes they had an impact on other senses. The libations were probably held according to a ritual scenario, which means they required specified skills and knowledge (social competences)*. It also seems that the celebration of sharing a meal expresses basic values of traditional societies. R. Kapuściński put it perfectly:

In Africa contact between people is a basic value. An African could not live alone. Even if they could survive in a material way, they would feel erased, discarded, degraded. Social life and being a part of a group give meaning to their own personality. It is a human immersed in a society, a small one, a bigger one (1999).

* Until the mid-20th century in Eastern Europe the ability to eat using a knife and a fork was not available to everyone. Its lack explicitly stigmatized a person as "uncouth".
It seems that fire was the most spectacular element of funerary rites. It was visually very attractive and it appears it was one of the reasons why various rituals that involved its use were so popular. Understanding the process of cremation as a kind of sacralization through the contact with fire is confirmed by written sources as well. Burnt offerings, described in the Bible many times, can be interpreted this way:

The sons of Aaron the priest are to put fire on the altar and arrange wood on the fire. Then Aaron's sons the priests shall arrange the pieces, including the head and the fat, on the wood that is burning on the altar. You are to wash the internal organs and the legs with water, and the priest is to burn all of it on the altar. It is a burnt offering, a food offering, an aroma pleasing to the LORD. Leviticus, 1, 7-9

What is important in the process, the attention was focused on the role of smoke, which is also a visually attractive element. It can be regarded as a transmitter - it ascended from the ground to the sky, together with an appropriate message:

These are the regulations for the grain offering: Aaron's sons are to bring it before the LORD, in front of the altar. The priest is to take a handful of the finest flour and some olive oil, together with all the incense on the grain offering, and burn the memorial portion on the altar as an aroma pleasing to the LORD. Leviticus 6, 14-15.

This information indicates that fire was treated as a kind of mediator. It was the way of communication with the sacred sphere. These phenomena are also connected with the rituals of lighting a fire, which are to some extent possible to trace using archaeological methods. The finds include so-called bowl-shaped rocks, i.e., boulders with holes with a diameter of several to over ten centimeters which are traces of lighting a fire using a wooden drill (Almgren 1934, 206-207; Szafrański 1974, 373). In the area of Poland several dozen such objects were recorded (Baruch 1907; Gralak 1998), however, most of them were destroyed. Four such erratic boulders were found in Wichów, Żagań district (Geschwendt 1939a, 1939b, 1944). They were discovered at a mound burial ground of the Urnfield culture from Phase IV of the Bronze Age (Malinowski 1961, 336), which allowed defining their chronology.

Such holes as those on the described boulders are widely known in Europe (Fig. 4: E, F). They are especially common in Scandinavia and North- 
ern Germany (Almgren 1934, 237-247; Broendstedt 1962, 126-128; Capelle 1972, 1984). Fire drills are known from written sources from Vedic India (Witort 1906, 14) and ancient Greece (Graves 1974, 78). Such a device is depicted on a wall of the tomb in Kivik in Sweden (Fig. 4: A) (Bing 1915, 66; Goldhahn 2009, fig. 3: 8) from Phase II of the Bronze Age. Another ones are known from the Bronze Age Scandinavian and Alpine rock carvings (Fig. 4: B-C) (Almgren 1934, 148-149). In Kivik a drill during its use was depicted. Thanks to human figures depicted next to it, it is possible to estimate its size. It was a stilt, 1.5-2 $\mathrm{m}$ high, with perpendicular weights hanging at the top, which stabilized it while spinning. It is also visible that during an attempt to light a fire two people were setting it in motion. Fire drills on rock carvings discovered in the Alps look a bit different. These were vertical stilts with two or three horizontal bars, crowned with a perpendicular large log, bent at the sides. The bars were probably used for holding the drill when using it, while the perpendicular crowning log made it steady. The device, and especially it vertical drilling part, was probably made of hazel or oak canes. This is indicated by the traditions of lighting fire using those tree species (Matusiak 1908, 44; A. S. 1900, 143). Using a device of human size, which was able to cause ignition through rotation, was also a kind of show. There was also a clearly defined scenario the rotation was supposed to end up with the emergence of a flame. Thus, it was not a purely pragmatic act of lighting a fire, which can be achieved in a much easier way. The action had to be visible. The drill can be therefore perceived as a prop of truly "theatrical" character.

The localization of the finds from Poland and the scene from the tomb in Kivik clearly suggest that there is a connection between fire drills and funerary rites. Flames kindled this way could have been used to light a funeral pyre with the dead. Such actions were probably repeated numerous times - that is why the holes we can see now could have been formed over many years. In the case of objects found beyond cemeteries it can be assumed that they served different functions. Ethnographic analogies indicate that lighting a fire was a very important element of the so-called fire festivities connected with the yearly cycle (Frazer 1962, 476495). Until the nineteenth century a new fire was lit and taken to every homestead (Klimaszewska 1981, 138). A detailed description of acquiring such fire in the tradition of the Hutsuls was presented by S. Vincenz:

Only once a year and only on a mountain meadow a live watchfire is lit. Earlier it was also lit in the hut, on Maundy Thursday, called Żywny, and was kept until people headed towards the mountain meadows. The live watchfire on a mountain meadow is not lit with a flint or sulphur matches, yet in another ancient way. Here, a dry wooden circle is taken and at one end it is cut in a crosswise manner. In this crack a tinder is inserted and with this end the wood is put in a circular tight hole at the side of a vertical log, stuck in the ground. The second end of the wood is put in a hole of a slat which is supporting it, so that it would tightly turn in the log. Then the wood is wrapped in a strong twine and two people grab the two ends of the twine and set the wood in motion until it catches fire (Vincenz 2002, 18).

In Scandinavia and many other European countries it was popular to light fires during the summer solstice (Kalif 2007, 164). Numerous ethnographic accounts describe lighting a so-called live fire, acquired according to a specified ritual. The fire made as a result of using the drill was called in Scandinavia as "rubbing fire" or "twisting fire" (Kalif 2007, 183). New fire was also lit before starting a war and in order to change a bad situation, e.g., ward off plagues, famine, drought, excessive rainfall etc. (Matusiak 1908, 44). It is possible that similar rituals were popular in the Bronze Age as well. It is worth noting that in the Vedic religious tradition lighting a new fire, including the way of using a drill, is an integral part of a burnt offering (Jurewicz 2016a, 265-267). The frequent occurrence of traces of lighting fire among the petroglyphs in Scandinavia and on various kinds of boulders in continental Europe may be explained that way as well.

In the Vedic Indian tradition a drill was the attribute of god Agni (Witort 1906, 14; Kalif 2007, 71). Burning fire, in turn, was considered to be his direct hierophany (Eliade 1997, 135-137). The name of the god is explicitly connected with fire, which is clearly visible in other Indo-European languages: Latin - ignis; Lithuanian: ugnis; Polish: ogień (Kalif 2007, 71). What is characteristic, it was believed in India that he created gold (Rivers 1999, 50, 53), of which his body was also built (Eliade 1997, 136, RV IV, 3,1 i X, 20,9). The belief confirms the aforementioned assumption that burning the dead or decorating them with metal objects carried a very 
similar meaning. The Rig-Veda also uses a term that helps to understand the perception of fire. The Sanskrit word tapas means light and warm (from Sun and fire) and the state after drinking the ritual drink - soma (Jurewicz 2010, 292; 2016b, 26, 126, 209, 219, 235, 282). According to W. Kaelber the word also describes the process of destroying and consuming through warmth/heat, and in this way inflicting wounds is also defined. First of all, it is the way Agni acts - through sacrificial fire. Tapas has then a creative character as well. It sacralizes the offering through its direct contact with the heavenly sphere. Exactly the same processes occur during cremation of the dead (Kaelber 1979, 192-194).

At this point it is worth paying attention to the way an offering or a ritual was understood. It was not a kind of do ut des request (I give in order to receive). The life of a human on Earth is a repetition or imitation of the way the whole world functions. It is generally the same. This is how its micro- and macrocosmic aspects are manifested. A burnt offering and cremation of a body is only a way of participating in theatrum mundi. Thus, a human or a community reveal their presence. It is a kind of utterance (using words, gestures, and actions), through which they build their identity and determine their place in the world. It is very suggestively shown by agnihotra, described in the Vedic literature. It was celebrated every day during the sunrise and sunset, and it consisted of an offering of milk or butter placed in fire (Eliade 1997, 142; Jurewicz $2016 \mathrm{~b}, 311,320-321,517-519)$. This very simple performative act showed that everyday human life is consistent with the world order.

The finds from the Late Bronze Age indicate that it was the time of a kind of artistic explosion. The phenomenon manifested itself through different mediums. It seems that the process can be associated with breaking the taboo on figurative depictions. It was noticed that in such situations the level of artistic expression increases also in other fields (see: Goody 1997). Among members of the Urnfield culture musical instruments appear - rattles (Fig. 5: B) (Nowiński 2000), the Pan flute (Fig. 5: A), and possibly also other ones (see also: Gediga 2006, Pomberger 2016; Schmeiduch 2016). From the Danube region finds of ceramic masks (Hrala, Špaček 2001) as well as those made of human skulls (Furmánek, Veliačik, Vladár 1991, 293, fig. 39) are known. Ceramic representations of people and animals appear as well (see: Gediga 1970).
The figurine known as "Apollo from Gliniany" (Hensel 1988, 323, fig. 209) probably depicts a man in a mask with a beak and a phallus during erection (Fig. 5: C). It is possible that this is a representation of a man playing a ritual scene. Depictions of people dressed as birds - wearing wings and masks with long beaks are also known from Scandinavian rock carvings (Coles 1995, fig. 10.2: f, 10.3: g; Skogstrand 2006, 96, fig. 20).

Probably the so-called cult wagons (or cult carts) were used as props in paratheatrical activities. The objects are usually miniature wagons with three four-spoke wheels made of bronze (Fig. 5: D). Additionally, depictions of water birds or animal heads featured with semi-circular horns were placed on them. Probably they were supposed to pull the wagons. Such depictions can be interpreted as a visualization of the myth that describes the movement of the Sun across the sky in a wagon drawn by birds. What is characteristic, such wagons were fitted with an empty sleeve in which most probably wooden handles were inserted (simply sticks) (see: Gediga 1976, 173-174). We do not have enough information to be able to estimate their length. Those objects could have been moved on the ground or carried. The construction alone suggests that they were used to reenact the way the mythical wagon carrying the Sun travelled.

At the end of the Bronze Age, especially in the Hallstatt period, human figures forming narrative scenes began to appear on ceramic vessels (Gediga 1976, 102, fig. 12). It has been suggested that they can depict dancing people (Grossman, Popławska 2018), including dancing in a circle (Hensel 1988, 314, fig. 198), especially when placed regularly around a vessel. Such depictions (Fig. 6: A, B) are known, among others, from Tresta Rządowa, Tomaszów district (Oleszczak, Twardowski 2011, tabl. 40, c, d) or Wenecja, Żnin district (Zajączkowski 2000, fig. 3). Narrative scenes appear on the urns of the Pomeranian culture as well. It is assumed that they can depict funeral ceremonies, also involving the use of wagons (see: Kwapiński 1993). In this culture also urns with depictions of faces occur very frequently. It is suggested that those objects could have served an analogous function in a funerary ritual as props in theater (Kowalska 2003). All those phenomena are characteristic elements of the Early Iron Age.

In general, it can be stated that a large part of the social life of people in the Bronze Age was based 
on more or less ritualized, performative, and paratheatrical activities. The social play (action) often took place in a specified and specially prepared scenography. This is how a cemetery can be perceived. A social person was created using characterization, props, scenography, and ritualized actions. Those elements formed the participants - actors. In this way messages and values as well as religious beliefs were transferred. In this sense paratheatrical activities comprised space for amusement and sharing multisensual experience of events and meanings in the society of that time. Obviously, it was also a kind of socialization and control, as the participants were forced to behave in a defined way and the specified way of understanding the world was also thrust upon them.

This kind of paratheatrical activity and its understanding survived (at least to some extent) until the twentieth century in European folklore. Of course, due to ideological changes, the message changed as well - however, the way of acting was of a definitely more universal character. It seems that the description of traditional communities function- ing not so long ago in Poland can give the idea of the way of thinking typical of the Bronze Age:

Realization of a ritual constituted a situation that was qualitatively different from everyday situations. It is best expressed in those cases when a ritual is a reenactment of a myth, when it is a performance whose scenario is based on mythical events. Thus, the mythical reality is re-updated. The actors play the roles of heroes, mythical creatures, they do divine things, have the ability to influence the course of events in the world and regulate natural phenomena according to their own will. In the perception of peasant communities a ritual was not a show, an equivalent of theater, therefore something artificial yet authentic realization of a myth in a specified place and time (Tomiccy J. R. 1975, 152).

Generally, the research perspective outlined above allows for a different way of interpreting many types of archaeological artefacts. Above all, they begin to appear as things that are supposed to provide communication. They carry messages that can be read today as well.

\section{BIBLIOGRAFIA}

A. S. (1900). Niecenie ognia.... Lud, 1, 143.

Arystoteles (1988). Retoryka, Poetyka. Przełożyt i komentarzem opatrzyt Henryk Podbielski. Warszawa: PIW.

Almgren O. (1934). Nordische Felszeichnungen als religiose Urkunden. Frankfurt am Main: Moritz Diesterweg.

Ałpatow M. (1976). Historia sztuki, I. Starożytność. Warszawa: Arkady.

Angutek D. (2003). Magiczne źródło filozofii greckiej. Bydgoszcz: Oficyna Wydawnicza Epigram.

Baruch M. (1907). Boże stopki. Warszawa: E Wende i S-ka.

Bing J. (1915). Das Kivikdenkmal. Mannus, 7, 61-77.

Broendstedt J. (1962). Bronzezeit in Dänemark, t. 2. Neumünster: Wachholtz.

Buśko C. (1987). Rekonstrukcja niektórych elementów obrządku pogrzebowego ludności kultury łużyckiej. Silesia Antiqua, 29, 59-94.

Buśko C. (1993). Symboliczny obraz świata. Z badań nad kurhanami ludności kultury łużyckiej. Studia Archeologiczne, 24, 85-103.

Cabalska M. (1967). Ze studiów nad obrządkiem ciałopalnym w Europie przedhistorycznej. Zeszyty Naukowe
Uniwersytetu Jagiellońskiego, 149. Prace Archeologiczne, 8, 39-60.

Cabalska M. (1972). Ze studiów nad systemami religijnymi związanymi z obrządkiem ciałopalnym (próba rekonstrukcji). Wiadomości Archeologiczne, 38, 3-18.

Chausidis N. (2017). Македонските бронзи и религијата и митологијата на железнодобните заедници од Средниот Балкан. Skopje: Центар за истражување на Предисторијата.

Capelle T. (1972). Felsbilder in Nordwest Deutchland. Acta Archaelogica Kopenhagen, 42, 229-238.

Coles J. (1995). Rock art as a pictures show. W: K. Helskog, B. Olsen (red.), Perceiving rock art: social and political perspectives. ACRA: the Alta Conference on Rock Art (181-199). Oslo: Novus Forlag.

Czarnowski S. (1963). Podział przestrzeni i jej rozgraniczenie w religii i magii. W: N. Assorodobraj, S. Ossowski (red.), Dzieła 3 (221-236). Warszawa: PWN.

Czyborra I. (1997). Gefäßdeponierungen - Speise und Trank für Götter und Menschen. W: B. Hansel (red.), Gaben an die Götter. Schätze der Bronzezeit Europas (87-89). Berlin: SMPK 
Eliade M. (1996). Sacrum i profanum. O istocie religijności. Warszawa: Wydawnictwo KR.

Eliade M. (1997). Historia wierzeń i idei religijnych, $t .1$. Od epoki kamiennej do misteriów eleuzyńskich. Warszawa: Instytut Wydawniczy „Pax”.

Frazer J.G. (1962). Złota gałąź. Warszawa: PIW.

Furmánek V., Veliačik L., Vladár J. (1991). Slovensko v dobe bronzovej. Bratislava: Veda.

Gąssowski J. (1994). Prahistoria sztuki. Warszawa: Oficyna Wydawnicza Szczepan Szymański.

Gediga B. (1970). Motywy figuralne w sztuce ludności kultury tużckiej. Wrocław: Zakład Narodowy im. Ossolińskich.

Gediga B. (1976). Śladami religii Prasłowian. WrocławWarszawa-Kraków-Gdańsk: Zakład Narodowy im. Ossolińskich.

Gediga B. (1978). Starszy okres epoki brązu na zachodnich ziemiach polskich w zasięgu 'kultury przedłużyckiej'. W: J. Machnik, B. Gediga, J. Miśkiewicz, W. Hensel (red.), Prahistoria Ziem Polskich, t. III, Wczesna epoka brązu (137-172). Wrocław-Warszawa-KrakówGdańsk: Ossolineum.

Gediga B. (2003). Bemerkungen zur Rolle der Karpaten in Beziehungen zwischen Süden und Norden in den frühen Bronzeperioden. W: C. Kacsó, A. Vulpe (red.), Bronzezeitliche Kulturerscheinungen im Karpatischen Raum. Die Beziehungen zu den benachbarten Gebieten: Ehrensymposium für Alexandru Vulpe zum 70. Geburtstag, Baia Mare, 10.-13. Oktober 2001 (171181). Baia Mare: Muzeul Județean Maramureş.

Gediga B. (2006). O muzykowaniu w epoce brązu i we wczesnej epoce żelaza w Europie. Kopiowanie rzeczywistości w sztuce. W: M. Kwapiński (red.), Estetyka $w$ archeologii. Kopie i naśladownictwa (85-105). Gdańsk: Muzeum Archeologiczne w Gdańsku.

Gediga B., Józefowska A. (2018). Cmentarzysko wczesnej epoki żelaza w Domasławiu 10/11/12, powiat wrocławski. T. I-III. Wrocław: Instytut Archeologii i Etnologii Polskiej Akademii Nauk.

Gediga B., Józefowska A. (2019). Przemiany obrzadku grzebalnego w epoce brąu $i$ wczesnej epoce żelaza $w$ świetle analizy źródel z cmentarzyska w Domasławiu, pow. wroctawski i nekropolii bliskiego rejonu (problemy zmian społeczno-kulturowych). Wrocław: Instytut Archeologii i Etnologii Polskiej Akademii Nauk.

Gedl M. (1975). Kultura przedtużycka. Wrocław-Warszawa-Kraków-Gdańsk: Zakład Narodowy im. Ossolińskich Wydawnictwo Polskiej Akademii Nauk.

Geschwendt F. (1939a). Ein schlesischen Opferstein. Altschlesiche Blätter, 14, 138-139.
Geschwendt F. (1939b). Der Napfschenstein von Neudorf Kr. Freystadt. Nachrichtenblatt für Deutsche Vorzeit, 15, 124-125.

Geschwendt F. (1944). Die bedeutendtsten Napfschensteine Niederschlesien. Altschlesiche Blätter, 19, 20-21.

Goldhahn J. (1999). Sagaholm - hällristningar och gravritual. Studia Archaeologica Universitatis Umensis, 11. Jönköping: AB Småland Quebecor.

Goldhahn J. (2009). Bredarör on Kivik: a monumental cairn and the history of its interpretation. Antiquity, 83, 359-371.

Goody J. (1997). Representations and Contradictions. Ambivalence towards images, theatre, fiction, relics and sexuality. Oxford: Blackwell.

Gralak T. 1998. Kamień jako hierofania $w$ pradziejach $i$ wczesnym średniowieczu ziem polski. Wrocław: Archiwum Instytutu Archeologii Uniwersytetu Wrocławskiego (maszynopis).

Gralak T. (2007). Osadnictwo ludności kultury unietyckiej na stan. Wojkowice 15, gm. Żórawina, pow. Wrocław. W: B. Gediga (red.), Archeologiczne Zeszyty Autostradowe, z. 5. Badania na autostradzie A4, cz. III (131304). Wrocław: Zespół Badań Ratowniczych IAiE PAN.

Gralak T. (2009a). Ślady pobytu ludności kultury unietyckiej na stanowiskach Piskorzówek 11 i 14, w gm. Domaniów, w powiecie oławskim. W: B. Gediga (red.), Archeologiczne Zeszyty Autostradowe, z. 9. Badania na autostradzie A4, cz. VII (7-20). Wrocław: Zespół Badań Ratowniczych IAiE PAN.

Gralak T. (2009b). Pochówki głów ludzkich z wczesnego okresu epoki brązu ze stanowiska Wojkowice $15 \mathrm{w}$ powiecie wrocławskim. W: B. Gediga (red.), Archeologiczne Zeszyty Autostradowe, z. 9, Badania na autostradzie A4, cz. VII (21-27). Wrocław: Zespół Badań Ratowniczych IAiE PAN.

Gralak T. (2011). Pochówki bydlęce i depozyty kości zwierzęcych ze stanowisk kultury unietyckiej na Śląsku. Śląskie Sprawozdania Archeologiczne, 53, 211-223.

Gralak T. (2015). The structure and style - a cultural border in central Poland in period II of the Bronze Age. W: P. Suchowska-Ducke, S. Scott Reiter, H. Vandkilde (red.), Forging Identities. The Mobility of Culture in Bronze Age Europe. Report from a Marie Curie Project 2009-2012 with Concluding Conference at Aarhus University, Volume 2 (193-200). BAR International Series 2772. Oxford: British Archaeological Reports.

Gralak T. (2018). Architecture, style and structure in the Early Iron Age in Central Europe. Wrocław: Instytut Archeologii Uniwersytetu Wrocławskiego. 
Graslund B. (1994). Prehistoric Soul Beliefs in Northern Europe. Proceedings of the Prehistoric Society, 60, $15-26$.

Graves R. (1974). Mity greckie. Warszawa: PIW.

Grossman A., Popławska D. (2018). Ryt(m) naczyniowy - intencje i konsekwencje. Zapis tańca z epoki brązu i żelaza. W: B. Gediga, A. Grossman, W. Piotrowski (red.), Inspiracje i funkcje sztuki, pradziejowej $i$ wczesnośredniowiecznej (265-282). Biskupin-Wrocław: Muzeum Archeologiczne Biskupin; Polska Akademia Nauk Oddział Wrocław.

Grotowski J. (1979). Wędrowanie z teatrem źródeł. Dialog, 11/283, rok XXIV, 94-103.

Gumiński W. (1980). Kto wprowadził ciałopalenie w Europie Środkowej. Z otchłani wieków, 46/1, 11-17.

Hansen S. (2015). Aspects of bronze age art. W: S. Hansen, V.I. Molodin (red.), The bronze age art, Proceedings of international symposium April 15-19, 2013, Stralsund, Germany (141-158). Novosibirsk-Berlin: Institut arkheologii i ètnografii SO RAN.

Häusler A. (1977). Die Bestattungssitten der frühen Bronzezeit zwischen Rhein und oberer Wolga, ihre Voraussetzungen und ihre Beziehungen. Zeitschrift für Archäologie, 11, 13-48.

Hensel W. (1988). Polska starożytna. Wrocław-WarszawaKraków-Gdańsk-Łódź: Zakład Narodowy im. Ossolińskich.

Herbert E.W. (1984). Red Gold of Africa: Copper in Precolonial History and Culture. Madison: University of Wisconsin Press.

Hezjod (1999). Narodziny bogów (Theogonia). Prace $i$ dni. Tarcza. Przełozyl, wstepem i przypisami opatrzyt Jerzy Łanowski. Warszawa: Prószyński i S-ka.

Homer (1990). Iliada. Przełożyt Franciszek Ksawery Dmochowski z oryginatem skolacjonowat, opracowat, komentarzem opatrzyt i aneks zestawit Zygmunt Kubiak. Warszawa: PIW.

Horst F. (1977). Bronzezeitliche Speiseopfer in Gefässen. W: B. Gediga, H. Hołubowicz, L. Leciejewicz (red.), Geneza kultury tuzyckiej na terenie Nadodrza (109148). Wrocław: Polska Akademia Nauk.

Hrala J., Špaček J. (2001). Ein spätebronzezeitlischer Maskenfund aus Mittelböhmen. W: B. Gediga, A. Mierzwiński, W. Piotrowski (red.), Sztuka epoki brązu $i$ wczesnej epoki żelaza w Europie Środkowej (213218). Wrocław-Biskupin: Polska Akademia Nauk Oddział Wrocław.

Jurewicz J. (2010). Fire and cognition in the Rgveda. Warszawa: Dom Wydawniczy Elipsa.

Jurewicz J. (2016a). Etymologies in the Brāhmaṇas and the Rgveda: A Case Study of 'Fire's Precedence'.
W: P. Koskikallio, A. Parpola (red.), Papers of the 12th world sanskrit conference held in Helsinki, Finland, 13-18 july 2003, t. 1 (251-270). Delhi: Motilal Banarsidass Publishers.

Jurewicz J. (2016b). Fire, death and philosophy: a history of ancient Indian thinking. Warszawa: Dom Wydawniczy Elipsa.

Kadrow S. (2001). U progu nowej epoki. Gospodarka i spoteczeństwo wczesnego okresu epoki brąu w Europie Środkowej. Kraków: Instytut Archeologii i Etnologii Polskiej Akademii Nauk.

Kaelber W.O. (1979). Tapas and Purification in Early Hinduism. Numen, 26/2, 192-214.

Kalif A. (2007). Fire, Water, Heaven and Earth. Ritual practice and cosmology in ancient Scandinavia: An Indo-European perspective. Lund: Riksantikvarieämbetet.

Kapuściński R. (1999). Opisuję stany ducha. Gabriela Łęcka, wywiad z Ryszardem Kapuścińskim. Polityka, luty 1999.

Klimaszewska J. (1981). Doroczne obrzędy ludowe. W: M. Biernacka, M. Frankowska, W. Paprocka (red.), Etnografia Polski. Przemiany kultury ludowej (127153). Wrocław: Zakład Narodowy im. Ossolińskich.

Kocur M. (2013). Źródła teatru. Wrocław: Wydawnictwo Uniwersytetu Wrocławskiego.

Kolankiewicz L. (1999). Dziady. Teatr święta zmartych. Gdańsk: Słowo Obraz Terytoria.

Kowalska M. (2003). Urny kultury pomorskiej jako „rekwizyty” w dramaturgii obrzędu pogrzebowego. W: B. Gediga, A.P. Kowalski (red.), Estetyka $w$ archeologii (29-35). Gdańsk: Muzeum Archeologiczne w Gdańsku.

Kowalski A.P. (1999). Symbol w kulturze archaicznej. Poznań: Wydawnictwo Naukowe Instytutu Filozofii UAM.

Kowalski A.P. (2001). Myślenie przedfilozoficzne. Poznań: Wydawnictwo Fundacji Humaniora.

Kowalski A.P. (2014). Antropologia zamierzchlych znaczeń. Toruń: Polskie Towarzystwo Historyczne.

Kristiansen K. (2013). Religion and society in the Bronze Age. W: L. Bredholt Christensen, O. Hammer, D.A. Warburton (red.), The Handbook of Religions in Ancient Europe (77-92). Londyn: Routledge.

Kristiansen K., Larsson T.B. (2005). The rise of Bronze Age society: travels, transmissions and transformations. Cambridge: Cambridge University Press.

Kulczycka-Leciejewiczowa A. (1979). Pierwsze społeczeństwa rolnicze na ziemiach polskich. Kultury kręgu naddunajskiego. W: W. Hensel, T. Wiślański (red.), 
Prahistoria Ziem Polskich, t. II. Neolit (19-164). Wrocław-Warszawa-Kraków-Gdańsk: Ossolineum.

Kwapiński M. (1993). Wozy w kulturze pomorskiej. Pomorania Antiqua, 15, 1-28.

Lorencova A., Beneš J., Podborsky V. (1987). TěšeticeKyjovice III. Únětycke pohřebište. Brno: Universita J. E. Purkyně v Brně.

Makarowicz P. (2017). The birth of a new world. Barrows, warriors, and metallurgists. W: P. Urbańczyk (red.), The past societies. Polish lands from the first evidence of human presence to the Early Middle Ages, vol. 3, (2000-500 BC) (128-186). Warszawa: Instytut Archeologii i Etnologii PAN.

Makiewicz T. (1993). Z badań nad ofiarami i miejscami ofiarnymi na terenie Polski w okresie przedrzymskim i rzymskim. W: M. Kwapiński, H. Paner (red.), Wierzenia przedchrześcijańskie na ziemiach polskich (6576). Gdańsk: Muzeum Archeologiczne w Gdańsku.

Malinowski T. (1961). Katalog cmentarzysk ludności kultury tużyckiej w Polsce, t. 1. Warszawa: Polska Akademia Nauk. Instytut Historii Kultury Materialnej.

Marciniak A. (1996). Archeologia i jej źródta. Materiaty faunistyczne w praktyce badawczej archeologii. Łódź: Wydawnictwo Naukowe PWN.

Marinatos N. (2009). Minoan kingship and the solar goddess. A Near Eastern Koine. Urbana: University of Illinois Press.

Matusiak S. (1908). Olimp polski według Długosza. Lud, 14, 19-89.

Mickiewicz A. (1992). Dziady. W: Dzieła poetyckie 3. Warszawa: Czytelnik.

Mierzwiński A. (2010). Pola popielnicowe - eschatologiczne aspekty antropomorfizacji metalurgii. W: E. Bugaj, A.P. Kowalski (red.), Estetyka $w$ archeologii Antropomorfizacje $w$ pradziejach $i$ starożytności (93-114). Poznań: Wydawnictwo Poznańskie.

Mierzwiński A. (2012a). Tajemnice pól popielnicowych. Pogranicze doczesności w perspektywie pradziejowej antropologii śmierci. Wrocław: Instytut Archeologii i Etnologii PAN - Ośrodek Badań nad Kulturą Późnego Antyku i Wczesnego Średniowiecza.

Mierzwiński A. (2012b). Biesiady w rytuale pogrzebowym nadodrzańskiej strefy pól popielnicowych. Wrocław: Instytut Archeologii i Etnologii PAN - Ośrodek Badań nad Kulturą Późnego Antyku i Wczesnego Średniowiecza.

Moszyński K. (1967). Kultura ludowa Stowian, t. 1. Kultura materialna. Warszawa: Książka i Wiedza.

Niesiołowska-Wędzka A. (1980). Procesy urbanizacyjne w kulturach wczesnej i środkowej epoki brązu na terenie Kotliny Karpackiej w świetle oddziaływań kręgu kultur egejsko-bałkańskiego. Archeologia Polski, 25, 29-78.

Nowiński J.T. (2000). Grzechotki ludności kultury łużyckiej w kontekście przestrzeni sakralnej. W: D. Piotrowska, B. Gediga (red.), Kultura symboliczna kręu pól popielnicowych epoki brąu $i$ wczesnej epoki żelaza w Europie środkowej (259-272). Warszawa-WrocławBiskupin: Muzeum Archeologiczne Biskupin; Polska Akademia Nauk Oddział Wrocław.

Oleszczak Ł., Twardowski W. (2011). Tresta Rządowa, stanowisko 1. Cmentarzysko kultury tużyckiej z Polski Środkowej, Ocalone Dziedzictwo Archeologiczne 1. Pękowice-Kraków. Wydawnictwo i Pracownia Archeologiczna Profil; Instytut Archeologii Uniwersytetu Jagiellońskiego.

Pismo Święte Starego i Nowego Testamentu. Wydanie ilustrowane. (2000). Warszawa-Poznań: Pallottinum.

Peterson Royse A. (2010). Antropologia Sztuk Widowiskowych. Artyzm wirtuozeria i interpretacja $w$ perspektywie międzykulturowej. Warszawa: Wydawnictwa Uniwersytetu Warszawskiego.

Pomberger B.M. (2016). The Development of Musical Instruments and Sound Objects from the Late Bronze Age to the La Tène Period in the Area between the River Salzach and the Danube Bend. W: B. Gediga, A. Grossman, W. Piotrowski (red.), Europa $w$ okresie od VIII w. p.n. Chr. do I w. n.e. (45-76). Biskupin-Wrocław: Muzeum Archeologiczne w Biskupinie, Komisja Archeologiczna Wrocławskiego Oddziału PAN, Instytut Archeologii i Etnologii PAN.

Popko M. (1980). Religie starożytnej Anatolii. Warszawa: Iskry.

Primas M. (1977). Untersuchungen zu den Bestattungssitten der ausgehenden Kupfer- und frühen Bronzezeit. Berichte der Römmisch Germanischen Kommission, 58, $1-160$.

Rivers V.Z. (1999). The Shining Cloth: Dress and Adornment That Glitters. London: Thames \& Hudson.

Rutkowski B. (1990). Sztuka minojska i mykeńska. W: Sztuka Świata, t. 2 (7-34). Warszawa: Arkady.

Sarnowska W. (1969). Kultura unietycka w Polsce, t. 1. Wrocław-Warszawa-Kraków: Zakład Narodowy im. Ossolińskich.

Schliemann H. (1878). Mycenae; a narrative of researches and discoveries at Mycenae and Tiryns. London: Murray.

Schmeiduch K. (2016). Rasseln der Lausitzer Kultur in Deutschland und Polen. W: B. Gediga, A. Grossman, W. Piotrowski (red). Europa w okresie od VIII w. przed Chr. do I w. n.e. (77-85). Biskupin-Wrocław: Muzeum Archeologiczne w Biskupinie, Komisja Archeologicz- 
na Wrocławskiego Oddziału PAN, Instytut Archeologii i Etnologii PAN.

Segal Ch. (2000). Słuchacz i widz. W: J.-P. Vernant (red.), Człowiek Grecji (221-260). Warszawa: Świat Książki.

Skogstrand L. (2006). I krig og evighet? Kjønnsideologiske forestillinger i yngre bronsealder og eldre førromersk jernalder belyst gjennom graver og helleristninger i Østfold. W: C. Prescott (red.), Kjønnsideologi og kosmografi $i$ den østnorske bronsealder. Oslo arkeologiske serie (15-168). Oslo: Institutt for arkeologi, kunsthistorie og konservering, Universitetet i Oslo.

Romanow J. (1973). Cmentarzysko ludności kultury unietyckiej. W: J. Romanow, K. Wachowski, B. Miszkiewicz, Tomice, pow. Dzierżoniów, wielokulturowe stanowisko archeologiczne (101-152). Wrocław-Warszawa-Kraków-Gdańsk: Zakład Narodowy im. Ossolińskich.

Stomma L. (2008). A jeśli było inaczej... Antropologia historii. Poznań: Wydawnictwo Sens.

Szafrański W. (1974). Zwyczaje, obrzędy i symbole religijne w dawnej Europie. W: B. Kupis (red.), Zwyczaje, obrzędy $i$ symbole religijne (353-402). Warszawa: Iskry.

Szafrański W. (1987). Prahistoria religii na ziemiach polskich. Wrocław-Warszawa-Kraków-Gdańsk-Łódź: Zakład Narodowy im. Ossolińskich.

Szmukier L. (1980). Stosunki kulturowe w Polsce południowo-zachodniej na przełomie wczesnej i starszej epoki brązu (stan badań). Archeologia Polski, 25, 7-28.

Treherne P. (1995) The warrior's beauty: the masculine body and self-identity in Bronze-Age Europe. Journal of European Archaeology, 3/1, 105-144.

Tomiccy J. R. (1975). Drzewo życia. Ludowa wizja świata i człowieka. Warszawa: Ludowa Spółdzielnia Wydawnicza.
Vernant J.-P. (2000). Człowiek Grecji. W: (red.), Człowiek Grecji (5-30). Warszawa: Świat Książki.

Vincenz S. (2002). Na wysokiej połoninie. Prawda starowieku. Sejny: Fundacja „Pogranicze”.

Wiślański T. (1979a). Kształtowanie się miejscowych kultur rolniczo-hodowlanych. Plemiona kultury pucharów lejkowatych. W: W. Hensel, T. Wiślański (red.), Prahistoria Ziem Polskich, t. II. Neolit (165-260). Wrocław-Warszawa-Kraków-Gdańsk: Zakład Narodowy im. Ossolińskich.

Wiślański T. (1979b). Dalszy rozwój ludów neolitycznych. Plemiona kultury amfor kulistych. W: W. Hensel, T. Wiślański (red.), Prahistoria Ziem Polskich, t. II. Neolit (261-300). Wrocław-Warszawa-Kraków-Gdańsk: Zakład Narodowy im. Ossolińskich.

Witort J. (1906). Filozofia pierwotna i animistyczna. Lud, $7,1-29$.

Woźny J. (2005). Czerwona ochra i ziarna zbóż. Symbolika odrodzenia zmartych w obrzędach pogrzebowych kultur archaicznych międzymorza baltycko-pontyjskiego. Bydgoszcz: Wydawnictwo Akademii Bydgoskiej im. Kazimierza Wielkiego.

Wygotski L. (1989). Myślenie i mowa. Warszawa: PWN.

Zajączkowski W. (2000). Naczynie kultury łużyckiej ze sceną figuralną z Wenecji Górnej, woj. bydgoskie. W: D. Piotrowska, B. Gediga (red.), Kultura symboliczna kręgu pól popielnicowych epoki brązu i wczesnej epoki żelaza w Europie środkowej (201-208). Warszawa-Wrocław-Biskupin: Muzeum Archeologiczne w Biskupinie, Komisja Archeologiczna Wrocławskiego Oddziału PAN, Instytut Archeologii i Etnologii PAN.

Żygulski Z. jun. (1998). Broń starożytna. Grecja, Rzym, Galia, Germania. Warszawa: Krajowa Agencja Wydawnicza.

Otrzymano (Received): 15.11.2019; Zrecenzowano (Revised): 6.02.2020; Zaakceptowano (Accepted): 9.03.2020

Adres Autora:

Dr hab. Tomasz Gralak

Instytut Archeologii Uniwersytetu Wrocławskiego

ul. Szewska 48

50-139 Wrocław PL

e-mail: tomasz.gralak@uwr.edu.pl

(iD https://orcid.org/0000-0002-8140-7245 
